\title{
Photocatalytic Activity and Characterization of Carbon-Modified Titania for Visible-Light-Active Photodegradation of Nitrogen Oxides
}

\author{
Chun-Hung Huang,, ${ }^{1}$ Yu-Ming Lin,, ${ }^{2}$ I-Kai Wang, ${ }^{3}$ and Chun-Mei Lu ${ }^{4}$ \\ ${ }^{1}$ Product Development Division, Daxin Material Co., No. 15, Keyuan 1st Road, Central Taiwan Science Park, Taichung 40763, Taiwan \\ ${ }^{2}$ ITRI South, Industrial Technology Research Institute, Room 602, Building 3, 31 Gongye 2nd Road, Annan District, \\ Tainan 70955, Taiwan \\ ${ }^{3}$ Department of Chemical Engineering, National Tsing-Hua University, Hsinchu 30043, Taiwan \\ ${ }^{4}$ Department of Chemical and Materials Engineering, National Chin-Yi University of Technology, Taichung 41101, Taiwan
}

Correspondence should be addressed to Yu-Ming Lin, yuminglin@itri.org.tw and I-Kai Wang, ikwang@che.nthu.edu.tw

Received 15 July 2011; Revised 24 October 2011; Accepted 24 October 2011

Academic Editor: Jinlong Zhang

Copyright (๑) 2012 Chun-Hung Huang et al. This is an open access article distributed under the Creative Commons Attribution License, which permits unrestricted use, distribution, and reproduction in any medium, provided the original work is properly cited.

\begin{abstract}
A variety of carbon-modified titania powders were prepared by impregnation method using a commercial available titania powder, Hombikat UV100, as matrix material while a range of alcohols from propanol to hexanol were used as precursors of carbon sources. Rising the carbon number of alcoholic precursor molecule, the modified titania showed increasing visible activities of $\mathrm{NO}_{x}$ photodegradation. The catalyst modified with cyclohexanol exhibited the best activities of $62 \%, 62 \%, 59 \%$, and $54 \%$ for the total $\mathrm{NO}_{x}$ removal under UV, blue, green, and red light irradiation, respectively. The high activity with long wavelength irradiation suggested a good capability of photocatalysis in full visible light spectrum. Analysis of UV-visible spectrum indicated that carbon modification promoted visible light absorption and red shift in band gap. XPS spectroscopic analysis identified the existence of carbonate species $(\mathrm{C}=\mathrm{O})$, which increased with the increasing carbon number of precursor molecule. Photoluminescence spectra demonstrated that the carbonate species suppressed the recombination rate of electron-hole pair. As a result, a mechanism of visible-light-active photocatalyst was proposed according to the formation of carbonate species on carbon-modified $\mathrm{TiO}_{2}$.
\end{abstract}

\section{Introduction}

In the field of environmental protection, photocatalysis is believed to have an extraordinary potential to treatment of contaminating compounds in water purification and air pollutants control, such as degradation of nitrogen oxides $\left(\mathrm{NO}_{x}\right)$, sulfur oxides $\left(\mathrm{SO}_{x}\right)$, and volatile organic compounds (VOCs) [1-5]. Among the semiconductors, titania has been regarded as the most promising material for photocatalysis due to its several advantages, including complete mineralization without other derivative chemicals, solar-light-induced operation at room temperature, non-toxicity, and low cost $[6,7]$. Generally, titania may exist in three different forms of crystalline phases: rutile, brookite, and anatase phase [8]. Rutile is thermodynamically stable and formed after calcination over $600^{\circ} \mathrm{C}$ with dense structure, resulting in low photocatalytic efficiency $[9,10]$. Brookite and anatase are structures of metastable states, whereas the former is not stable enough to exist alone. Anatase is recognized as the most suitable phase for photocatalysis [5]. However, with the band gap of $3.2 \mathrm{eV}$, anatase phase $\mathrm{TiO}_{2}$ can be photoactivated under UV light irradiation (wavelength shorter than $388 \mathrm{~nm}$ ), which only accounts for $4 \%$ of the solar spectrum. To extend the utilization over the main part (45\%) of visible region in solar spectrum, several attempts have been made to reduce the band gap.

One strategy is preparing metal-modified titania by doping or loading transitional metals, such as $\mathrm{V}, \mathrm{Mn}, \mathrm{Fe}$, $\mathrm{Cr}, \mathrm{Cu}, \mathrm{Ni}, \mathrm{W}$, and others [11-15]. The noble metals were reported to produce the highest Schottky barrier and to facilitate electron capture [16]. Therefore, $\mathrm{Ag}, \mathrm{Ru}$, and $\mathrm{Pt}$ [17-21] were employed to modify $\mathrm{TiO}_{2}$ for enhancing UV photocatalytic efficiency and/or visible light activities. 
Nonmetal doping is the other approach to achieve the goal of $\mathrm{TiO}_{2}$ modification. Sato [22] discovered the redshift phenomena of $\mathrm{N}$-promoted $\mathrm{TiO}_{2}$. Afterward Asahi et al. [23] reported that a small amount of substitutional $\mathrm{N}$ atoms into the $\mathrm{TiO}_{2}$ structure by the sputtering method will induce the $\mathrm{Ti}^{3+}$ sites on the $\mathrm{TiO}_{2}$ surface and significantly narrow the band gap. Nakamura et al. [24] found that $\mathrm{TiO}_{2}$ treated with hydrogen plasma can generate oxygen vacancies and create subband gap to promote visible light response, despite the expensive appliance. Organic dyes as the light sensitization agents were also considered to be added on the $\mathrm{TiO}_{2}$ surface to improve the light efficiency $[25,26]$. However, the consumption of dye molecules during the reaction process will limit the application. Recently, carbon was widely used for visible modification of $\mathrm{TiO}_{2}$ [27-31]. It was reported that carbon modification is more efficient, even higher than nitrogen modification [28]. The carbon doped $\mathrm{TiO}_{2}$ could be prepared by simple method such as mechanochemical operation by grinding $\mathrm{TiO}_{2}$ with ethanol in air [32]. On a comprehensive survey, carbon is one of the practicable materials, for the consideration of economic and practical mass production. Therefore, in this study, we tried to use carbon precursors to modify $\mathrm{TiO}_{2}$ powder by impregnation method, enabling the significant visible photoactivity. Moreover, a possible photocatalytic mechanism was proposed to speculate the role of carbonaceous species functioning with $\mathrm{TiO}_{2}$, based on the evidences observed from various characterization techniques.

\section{Experimental}

2.1. Preparation of Carbon-Modified $\mathrm{TiO}_{2}$ Photocatalysts. All chemicals in this study are reagent-grade without further purification. A commercially available $\mathrm{TiO}_{2}$ powder (Hombikat UV100, Sachtleben Chemie, 100\% anatase), symbolized as UV100, was used as the matrix material for modification. Seven kinds of alcohols were adopted as the carbon sources: 2-propanol, n-propanol, 2-butanol, ibutanol, 4-methyl-2-pentanol, n-hexanol, and cyclohexanol, symbolized as 2-C3, C3, 2-C4, iC4, 2-C6, C6, and cC6, respectively, according to the carbon number of molecule and the isomer structure. Impregnation method was used to prepare carbon-modified $\mathrm{TiO}_{2}$. The synthesis procedures are depicted in Figure 1. Firstly, 5 g UV100 powder was added into an alcoholic solution containing $30 \mathrm{~mL}$ alcohol and $70 \mathrm{~mL}$ D.I. water. After ultrasonic bath for several minutes, the slurry was then magnetically stirred for $30 \mathrm{~min}$ with sufficient mixing. Subsequently, the modified sample was evaporated in an oven at $110^{\circ} \mathrm{C}$ for $4 \mathrm{~h}$ and then milled to powder, followed by calcination at a heating rate of $1^{\circ} \mathrm{C}$ $/ \mathrm{min}$ up to $200^{\circ} \mathrm{C}$ for $5 \mathrm{~h}$ in a furnace. Finally, seven kinds of carbon-modified $\mathrm{TiO}_{2}$ were obtained and symbolized as 2-C3/UV100, C3/UV100, 2-C4/UV100, iC4/UV100, 2C6/UV100, C6/UV100, and cC6/UV100, ascribed to their alcoholic precursors.

2.2. Experimental Apparatus and Procedure. Photocatalytic degradation of nitrogen oxides $\left(\right.$ De- $\left.\mathrm{NO}_{x}\right)$ was carried out at

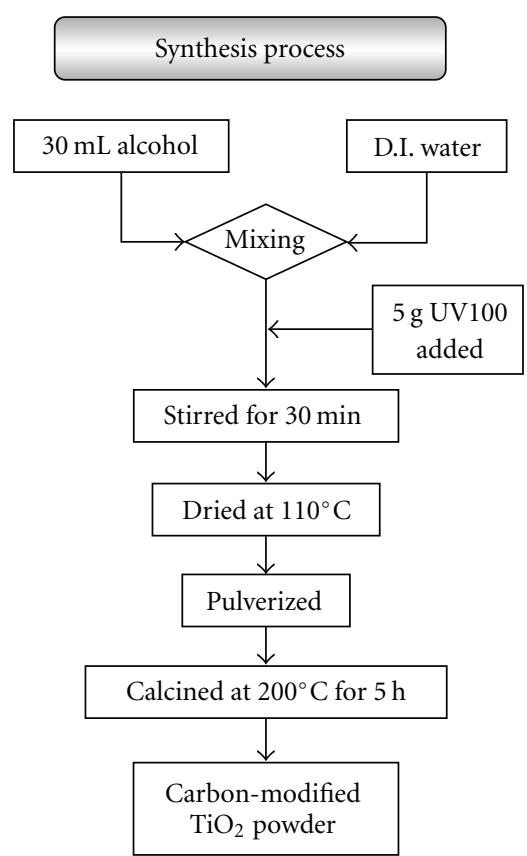

FIGURE 1: Schematic procedure for synthesis of carbon-modified $\mathrm{TiO}_{2}$ powder by impregnation method.

room temperature by the setup consisting of a continuous flow reactor (a round-shaped Pyrex glass vessel) connected to the gas suppliers and the analytic system, as shown in Figure 2. To simulate atmospheric environment and reach the optimal value, the relative humidity was maintained at $50 \%$ by adjusting a humidified air stream with a dry air stream [4]. Then, a nitric oxide (NO) gas stream, provided by a cylinder containing 100 ppmv NO (San Fu Chemical Co., $\mathrm{N}_{2}$ balance), was added to the air stream to reach a desired NO concentration of 1 ppmv and a total volumetric flow rate of $1 \mathrm{~L} / \mathrm{min}$ as the feedstock. The photocatalyst with amount of $0.5 \mathrm{~g}$ was dispersed into an appropriate amount of D.I. water contained in a $50 \mathrm{~mL}$ beaker, followed by well stirring. Then the mixed slurry was uniformly spread on a disk-like glass plate (diameter $=12 \mathrm{~cm}$ ). After drying at $110^{\circ} \mathrm{C}$ for $30 \mathrm{~min}$, dehydrated powder attached to the plate was obtained. Subsequently, the glass plate coated with the photocatalyst was set in the center of reactor for use. A UV light lamp over the reactor delivered the ultraviolet illumination in the wavelength range of 330-420 nm. For visible light reaction, three light-emitting diodes (LEDs) were employed, including blue LEDs (BLED, 430-530 nm), green LEDs (GLED, 470-570 nm), and red LEDs (RLED, 590$680 \mathrm{~nm}$ ). The related photon energy distribution profiles are shown in the inset of Figure 2. The intensity of the light source was controlled at $1 \mathrm{~mW} / \mathrm{cm}^{2}$ and was measured by a spectrophotometer (Ocean Optics, USB2000).

In a typical experiment, the feedstock was introduced to the reactor with sample plate for several minutes in the dark. Light was turned on as the system reached the adsorption equilibrium (i.e., NO concentration recovering to $1 \mathrm{ppmv}$ ). Meanwhile, the effluent concentrations of $\mathrm{NO}$ and nitrogen dioxide $\left(\mathrm{NO}_{2}\right)$ from reactor were measured 


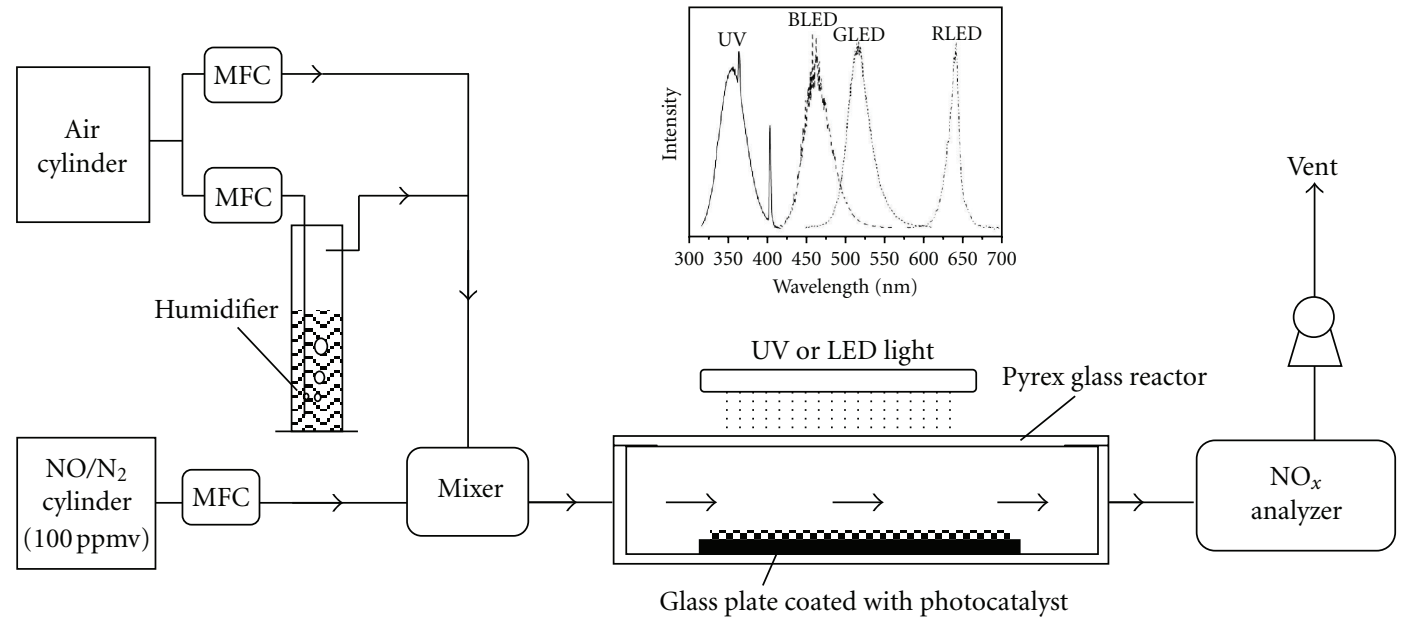

FIgURE 2: Schematic diagram of De-NO $\mathrm{NO}_{x}$ system. The inset shows photon energy distribution of UV lamp and LEDs.

by an on-line chemiluminescent $\mathrm{NO}_{x}$ analyzer (Eco Physics, CLD 700AL). In addition, blank test was performed under the same condition except photocatalyst existence. The result certainly guaranteed all the materials of the system inactive on photocatalytic De- $\mathrm{NO}_{x}$.

$\mathrm{NO}$ is oxidized in a serial steps $\left(\mathrm{NO} \rightarrow \mathrm{NO}_{2} \rightarrow \mathrm{NO}_{3}{ }^{-}\right.$) over the photocatalyst under illumination [4]. The final product, $\mathrm{NO}_{3}{ }^{-}$ion, was adsorbed on the photocatalyst surface and could be easily washed out by water for photocatalyst in reuse [17]. In data analysis, the total $\mathrm{NO}_{x}$ concentration $\left(\left[\mathrm{NO}_{x}\right]\right), \mathrm{NO}$ conversion $(\mathrm{NOC}), \mathrm{NO}_{2}$ selectivity $\left(\mathrm{NO}_{2} \mathrm{~S}\right)$, and total $\mathrm{NO}_{x}$ removal $\left(\mathrm{NO}_{x} \mathrm{R}\right)$ were defined as follows:

$$
\begin{gathered}
{\left[\mathrm{NO}_{x}\right]=[\mathrm{NO}]+\left[\mathrm{NO}_{2}\right],} \\
\mathrm{NO} \text { conversion }=\frac{[\mathrm{NO}]_{\text {in }}-[\mathrm{NO}]_{\text {out }}}{[\mathrm{NO}]_{\text {in }}}, \\
\mathrm{NO}_{2} \text { selectivity }=\frac{\left[\mathrm{NO}_{2}\right]_{\text {out }}}{[\mathrm{NO}]_{\text {in }}-[\mathrm{NO}]_{\text {out }}}, \\
\text { Total } \mathrm{NO}_{x} \text { removal }=\frac{[\mathrm{NO}]_{\text {in }}-\left[\mathrm{NO}_{x}\right]_{\text {out }}}{[\mathrm{NO}]_{\text {in }}} .
\end{gathered}
$$

The photocatalyst performance could be evaluated by the total $\mathrm{NO}_{x}$ removal, or the $\mathrm{NO}$ conversion conjunctive with the $\mathrm{NO}_{2}$ selectivity.

2.3. Characterization and Analysis. The particle sizes and the morphology of photocatalysts were examined by fieldemission scanning electron microscopy (FE-SEM, Hitachi S4800-1) and transmission electron microscopy (TEM, Philips Tecnai 20). Each powder sample was dispersed in anhydrous alcohol and then transferred to a copper grid (with carbon support film, 300-mesh). After drying at $50^{\circ} \mathrm{C}$ in an oven, the pretreatment was completed for use.
The specific surface areas (SSAs) were measured by nitrogen adsorption at $77 \mathrm{~K}$ using Micrometrics equipment (Model ASAP 2000). Samples were outgassed to a vacuum lower than $10^{-4}$ Torr at $200^{\circ} \mathrm{C}$ for $2 \mathrm{~h}$ to remove adsorbed impurities prior to each measurement. Specific surface areas were evaluated by Barrett-Emmet-Teller (BET) method [33].

The crystal structures were analyzed by an X-ray powder diffractometry (XRD, Rigaku RU-H3R) in the reflection mode with $\mathrm{Cu} \mathrm{K}_{\alpha}$ radiation. The angular domain was 20 $80^{\circ}(2 \theta)$. The surface structures were identified by a MicroRaman spectrometer (Renishaw 1000B), conducted with a low-power green laser $(100 \mathrm{~mW})$ at $532 \mathrm{~nm}$. Weak laser of $1 \%$ to $10 \%$ power was used to examine the surface structure of the samples.

The UV-visible absorption spectra of all samples were performed by a powder UV-visible spectrophotometer (UVVIS, Shimadzu UV-2450) equipped with an integrating sphere accessory for diffuse reflectance spectra over a range of 200-800 $\mathrm{nm}$ by using $\mathrm{BaSO}_{4}$ as the reference. The obtained reflectance data $(R)$ was converted to the absorbance value, $F(R)$, based on the Kubelka-Munk theory, as follows:

$$
F(R)=\frac{(1-R)^{2}}{2 R} .
$$

The surface composition and the chemical states of catalysts were investigated by an X-ray photoelectron spectroscopy (XPS, Physical Electronics ESCA PHI 1600) with $\mathrm{Mg} \mathrm{K}_{\alpha}$ radiation. The charging effects were corrected by adjusting the $\mathrm{C} 1 \mathrm{~s}$ peak to a position of $284.5 \mathrm{eV}$.

The decomposition behavior of products was determined by thermogravimetric analysis (TGA) using a thermogravimeter mass spectrometer (Seiko instruments, TG/DT 6200 ) at a heating rate of $10^{\circ} \mathrm{C} / \mathrm{min}$ between 200 to $800^{\circ} \mathrm{C}$ in flowing nitrogen. Samples (about $3 \mathrm{mg}$ ) were set and heated to $200^{\circ} \mathrm{C}$ for $30 \mathrm{~min}$ prior to each experiment.

The photoluminescence (PL) emission spectra were measured by using a Xe lamp with wavelength of $325 \mathrm{~nm}$ as an excitation light source. The reflectance spectra of the samples are over a range of $200-800 \mathrm{~nm}$. 


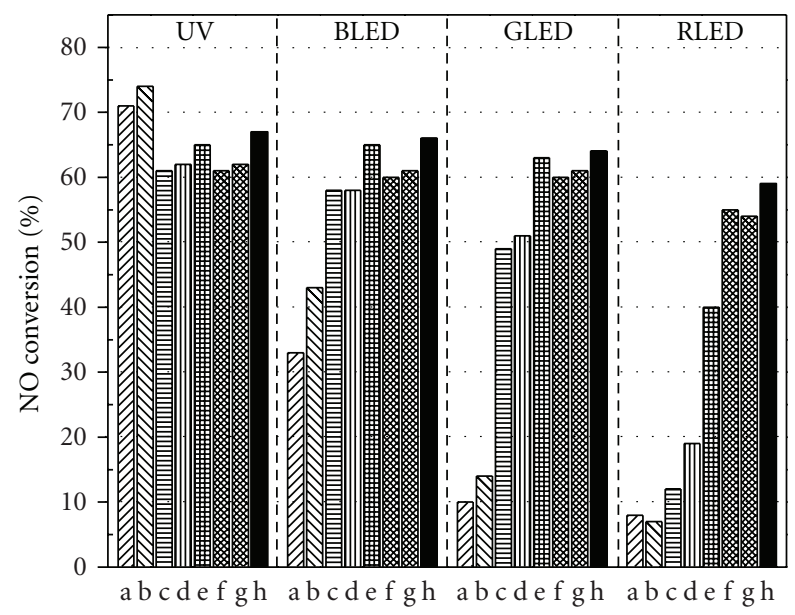

(A)

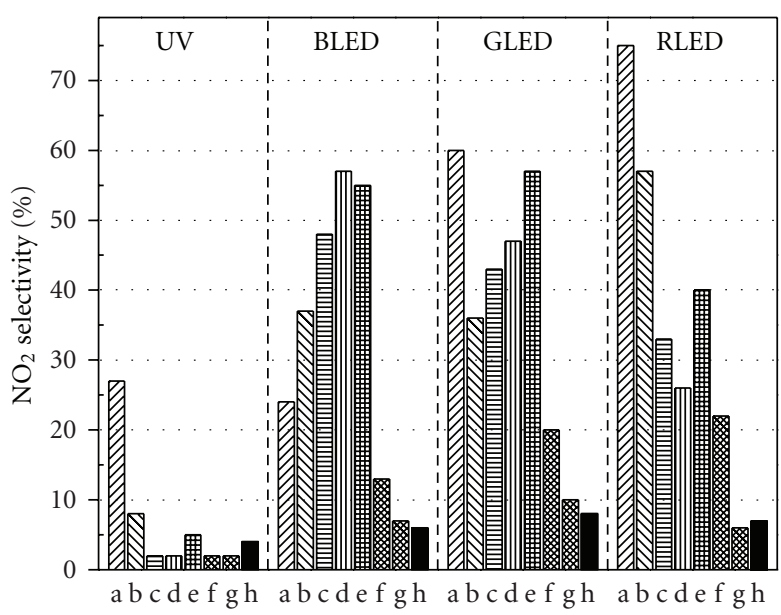

(B)

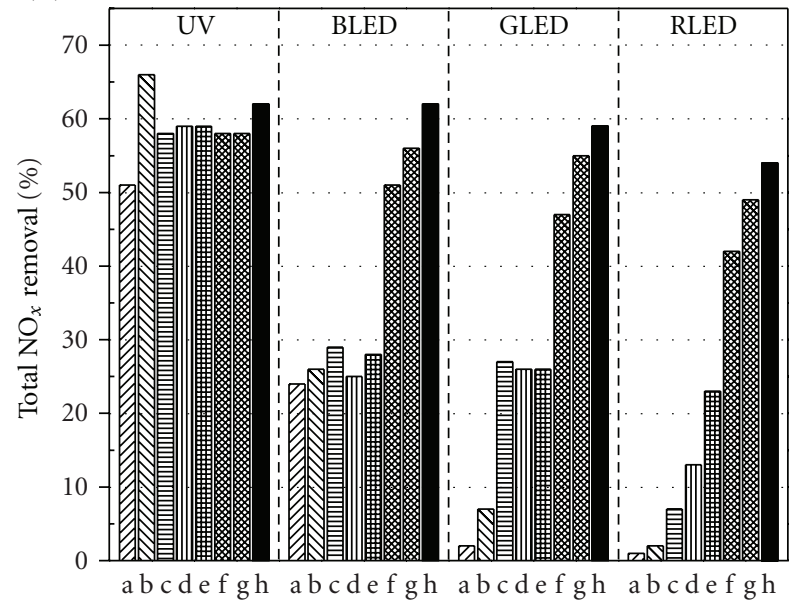

(C)

FIGURE 3: De- $\mathrm{NO}_{x}$ activities including NO conversion (A), $\mathrm{NO}_{2}$ selectivity (B), and total $\mathrm{NO}_{x}$ removal (C) on UV100 (a), 2-C3/UV100 (b), C3/UV100 (c), 2-C4/UV100 (d), iC4/UV100 (e), 2-C6/UV100 (f), C6/UV100 (g), and cC6/UV100 (h).

\section{Results and Discussion}

3.1. Photocatalytic Ativity of Carbon-Modified $\mathrm{TiO}_{2}$. The $\mathrm{NO}$ conversion (NOC), $\mathrm{NO}_{2}$ selectivity $\left(\mathrm{NO}_{2} \mathrm{~S}\right)$, and total $\mathrm{NO}_{x}$ removal $\left(\mathrm{NO}_{x} \mathrm{R}\right)$ on unmodified UV100 and carbonmodified UV100 under various light irradiations are illustrated in Figure 3. In a serial oxidation steps $(\mathrm{NO} \rightarrow$ $\mathrm{NO}_{2} \rightarrow \mathrm{NO}_{3}^{-}$), NOC, $\mathrm{NO}_{2} \mathrm{~S}$, and $\mathrm{NO}_{x} \mathrm{R}$ represent the initial oxidation of $\mathrm{NO}$ converted, the undesired byproduct ratio, and the total oxidation ability, respectively. Accordingly, a well-active photocatalyst should basically provide a high $\mathrm{NOC}$ as well as a low $\mathrm{NO}_{2} \mathrm{~S}$, resulting in a high $\mathrm{NO}_{x} \mathrm{R}$. With the same $\mathrm{NO}$ conversion, the one with lower $\mathrm{NO}_{2}$ selectivity catalyzed the oxidation of $\mathrm{NO}_{2}$ to $\mathrm{NO}_{3}{ }^{-}$more completely.

In UV light reaction, unmodified UV100 exhibited a high NOC (71\%) attributed to its pure anatase phase structure and high specific surface area [34]. However, the high $\mathrm{NO}_{2} \mathrm{~S}$ revealed $(27 \%)$ the insufficiency in $\mathrm{NO}_{2}$ suppressive ability and led to the reduction of $\mathrm{NO}_{x} \mathrm{R}$ (51\%). Compared with UV100, carbon-modified UV100 showed a similar or slightlower NOC. It was referred that carbonaceous residues on $\mathrm{TiO}_{2}$ surface partly obstructed UV absorption, as evidenced in UV-VIS analysis (discussed later). Even so, carbon species probably functioned with $\mathrm{TiO}_{2}$ and substantially lowered the $\mathrm{NO}_{2} \mathrm{~S}$. As a result, all carbon-modified $\mathrm{TiO}_{2}$ displayed higher $\mathrm{NO}_{x} \mathrm{R}$ than UV100.

In visible light reaction, apparently UV100 provided poor activities, especially under GLED and RLED irradiation with the $\mathrm{NO}_{x} \mathrm{R}$ of $3 \%$ and $1 \%$, respectively. In contrast, carbon-modified UV100 showed progressive activity under whichever visible light irradiation. It suggested that the visible light response may be offered by the conjugation of carbonaceous residues and $\mathrm{TiO}_{2}$. Additionally, like the performance in UV reaction, $\mathrm{NO}_{2} \mathrm{~S}$ was also successfully suppressed on carbon-modified UV100 under visible light irradiation. Furthermore, the visible light activity increased with the increase of carbon number in alcoholic precursors. Visible-photocatalytic activities were in the order of UV $100<$ 2-C3/UV100 < C3/UV100 < 2-C4/UV100 < iC4/UV100 < 2$\mathrm{C6} / \mathrm{UV} 100<\mathrm{C6} / \mathrm{UV} 100<\mathrm{cC} 6 / \mathrm{UV} 100$. Among the products, cC6/UV100, prepared by modification of the highest carbon number in alcoholic precursor, exhibited the highest visible activity of $62 \%, 59 \%$, and $54 \%$ for BLED, GLED, and RLED reaction, respectively. Compared with its UV activity (62\%), 
TABLE 1: Characterization of the band gap, specific surface area, and weight loss in TGA.

\begin{tabular}{|c|c|c|c|c|c|c|}
\hline \multirow{2}{*}{ Sample } & \multirow{2}{*}{ Band gap ${ }^{\mathrm{b}}(\mathrm{eV})$} & \multirow{2}{*}{ Specific surface area $\left(\mathrm{m}^{2} / \mathrm{g}\right)$} & \multicolumn{4}{|c|}{ Weight loss ${ }^{\mathrm{a}}$ (wt.\%, between 200 and $800^{\circ} \mathrm{C}$ ) } \\
\hline & & & Total & $200-380^{\circ} \mathrm{C}$ & $380-600^{\circ} \mathrm{C}$ & $600-800^{\circ} \mathrm{C}$ \\
\hline UV100 & 3.26 & 249 & 4.23 & 2.33 & 1.01 & 0.90 \\
\hline $2-\mathrm{C} 3$ & 3.24 & 252 & 3.53 & 1.71 & 0.95 & 0.87 \\
\hline $\mathrm{C} 3$ & 3.24 & 272 & 4.84 & 2.10 & 2.18 & 0.57 \\
\hline $2-\mathrm{C} 4$ & 3.24 & 279 & 4.88 & 2.13 & 2.18 & 0.58 \\
\hline $\mathrm{iC} 4$ & 3.23 & 298 & 5.73 & 2.86 & 2.01 & 0.89 \\
\hline 2-C6 & 3.18 & 290 & 5.71 & 2.44 & 2.69 & 0.58 \\
\hline C6 & 3.07 & 294 & 7.73 & 3.70 & 3.18 & 0.86 \\
\hline cC6 & 3.04 & 297 & 6.82 & 2.91 & 3.27 & 0.64 \\
\hline
\end{tabular}

all samples were pretreated at $200^{\circ} \mathrm{C}$ before test.

${ }^{b}$ Determined by the intercept in Tauc Plot.

TABLE 2: The elemental surface composition and atomic ratio of $\mathrm{O} / \mathrm{Ti}$ resulted from XPS analysis.

\begin{tabular}{lccccc}
\hline Sample & $\mathrm{Ti}(\%)$ & $\mathrm{O}(\%)$ & $\mathrm{N}(\%)$ & $\mathrm{C}(\%)$ & $\mathrm{O} / \mathrm{Ti}$ \\
\hline UV100 & 15.7 & 58.9 & 1.4 & 24.0 & 3.8 \\
2-C3 & 20.6 & 52.7 & - & 26.7 & 2.6 \\
C3 & 18.8 & 49.9 & - & 31.3 & 2.7 \\
2-C4 & 16.7 & 49.3 & - & 34.0 & 3.0 \\
iC4 & 11.4 & 49.9 & - & 38.7 & 4.3 \\
2-C6 & 16.0 & 52.6 & - & 31.4 & 3.3 \\
C6 & 12.1 & 45.2 & - & 42.7 & 3.7 \\
cC6 & 14.0 & 42.3 & - & 43.7 & 3.0 \\
\hline
\end{tabular}

cC6/UV100 was stable enough to extend its photoactivity to visible region, even under red light irradiation. As can be seen in Tables 1-3, specific surface area, carbon amount, and C$\mathrm{C}$ and $\mathrm{C}=\mathrm{O}$ ratio obviously increase with increasing carbon number of alcoholic precursor. In addition, higher visible light absorbance and lower band gap were observed as the carbon number of alcoholic precursor increased (Figure 7). All these positive factors may contribute to the highest activity of cC6/UV100 catalyst.

In summary, via impregnation with alcoholic precursors followed by low temperature calcination at $200^{\circ} \mathrm{C}$, carbonaceous residues acted as sensitizing agent with $\mathrm{TiO}_{2}$ to lower $\mathrm{NO}_{2}$ production efficiently, facilitated more complete reaction, and improved the visible photoactivity. Visible activities increased with the rise of carbon number in precursor molecule. And with the same carbon number (e.g., $n=6$ ), photocatalytic levels were in the order of $2-C_{n}<$ $\mathrm{C}_{n}<\mathrm{cC}_{n}$, depending on the isomer structure. Therefore, the carbonaceous species resulted from different molecular structure of alcoholic precursors may play an important role on visible light activity.

\subsection{Characterization of Carbon-Modified $\mathrm{TiO}_{2}$}

3.2.1. Morphology. Figure 4 shows the FE-SEM and TEM images of various photocatalysts. FE-SEM photographs indicated that the primary particle size was unchanged
(7-14 nm) after carbon-modification, while the secondary particle was more agglomerate. From TEM photographs, it could be found that amorphous carbonaceous species exist on the interfaces or surface of $\mathrm{TiO}_{2}$. It may be the reason for high agglomeration of carbon-modified $\mathrm{TiO}_{2}$ catalysts.

3.2.2. Specific Surface Area. The specific surface areas of all samples were in range of $249-298 \mathrm{~m}^{2} / \mathrm{g}$ (Column 3 in Table 1). All the modified samples showed larger specific surface areas than UV100 $\left(249 \mathrm{~m}^{2} / \mathrm{g}\right)$. The higher the carbon number in precursor molecule was, the higher the specific surface area of the catalyst was obtained. Zhang et al. [35] investigated carbon-modified $\mathrm{TiO}_{2}$ by using glucose as precursor and mentioned that carbon residue did not make $\mathrm{TiO}_{2}$ growth. Same thing was observed in this study. Therefore, the carbonaceous species, existing on the $\mathrm{TiO}_{2}$ surface, may create more specific surface area and favor the photocatalytic efficiency.

3.2.3. Crystal Structure. The XRD patterns are shown in Figure 5. All the crystal structures of samples were almost anatase, attributed to several main peaks $(2 \theta=25.3$ with [101], 37.8 with [004], 48.1 with [200], 54.0 with [105], and 62.7 with [204]). There was no significant difference between samples, which meant that carbon modification did not obviously change the crystal phase through lowtemperature calcination. According to Scherrer's equation, the crystal size is larger with sharper main peak. All the crystal sizes of samples were in range of 9-12 nm, consistent with those observed in TEM graphs.

Raman spectrum is surface-sensitive for surface characterization. The Raman spectra of all samples are shown in Figure 6. Firstly, a weak laser power ( $1 \%$ of $100 \mathrm{~mW}$ ) was introduced as the source to detect Raman signals. As shown in Figure 6(a), all samples showed anatase peaks mainly. However, a shoulder peak at $480 \mathrm{~cm}^{-1}$ grew up with the increasing carbon number. It was attributed to brookite, regarded as a visible-light-responsive phase [36]. When the laser power was enhanced to $10 \%$ of $100 \mathrm{~mW}$, the brookite peak disappeared (Figure 6(b)) due to its characteristics of unstable phase. This phenomenon confirmed that the unstable phase was brookite. Moreover, $10 \%$ of $100 \mathrm{~mW}$ 
TABLE 3: Deconvolution results of C 1s and O 1s spectra from XPS analysis.

\begin{tabular}{|c|c|c|c|c|c|}
\hline \multirow{2}{*}{ Sample } & \multicolumn{2}{|c|}{ Deconvolution of C $1 \mathrm{~s}$ spectra $^{\mathrm{a}}$} & \multicolumn{3}{|c|}{ Deconvolution of $\mathrm{O} 1 \mathrm{~s}$ spectra ${ }^{\mathrm{b}}$} \\
\hline & $\begin{array}{c}\text { C-C ratio } \\
(\%)\end{array}$ & $\begin{array}{c}\mathrm{C}=\mathrm{O} \text { ratio } \\
(\%)\end{array}$ & $\begin{array}{c}\text { Ti-O ratio } \\
(\%)\end{array}$ & $\begin{array}{c}\mathrm{O}-\mathrm{H} \text { ratio } \\
(\%)\end{array}$ & $\begin{array}{c}\mathrm{C}=\mathrm{O} \text { ratio } \\
(\%)\end{array}$ \\
\hline UV100 & 22.6 & 1.4 & 47.2 & 10.7 & 1.0 \\
\hline $2-\mathrm{C} 3$ & 19.9 & 6.8 & 44.9 & 2.9 & 4.9 \\
\hline C3 & 22.8 & 8.5 & 42.5 & 2.7 & 4.7 \\
\hline $2-\mathrm{C} 4$ & 25.4 & 8.6 & 40.1 & 2.7 & 6.5 \\
\hline $\mathrm{iC} 4$ & 26.1 & 12.6 & 38.3 & 3.2 & 8.3 \\
\hline 2-C6 & 18.8 & 12.6 & 39.3 & 3.7 & 9.6 \\
\hline C6 & 29.2 & 13.4 & 33.4 & 2.6 & 9.1 \\
\hline cC6 & 31.4 & 12.3 & 28.1 & 3.1 & 11.1 \\
\hline
\end{tabular}

${ }^{a}$ Peaks fitted at $284.5-284.7 \mathrm{eV}$ and $287.2-287.6 \mathrm{eV}$ for $\mathrm{C}-\mathrm{C}$ and $\mathrm{C}=\mathrm{O}$ bonding.

${ }^{b}$ Peaks fitted at 529.3-529.9 eV, 530.9-531.5 eV, and 531.9-532.8 eV for Ti-O, O-H, and Ti=O bonding, respectively.

power was employed to treat the same sample for several times. The main crystal phase would transform from anatase to rutile (Figure 6(c)) over repeated treatment because the strong incident power might cause transformation to the ultimately stable phase, that is, rutile. Basically, UV100 was almost of anatase phase. After carbon impregnation, small portion of brookite phase was observed on UV100 surface. And visible light activities might be enhanced with the brookite phase.

3.2.4. UV-Visible Absorption. The apparent colors are whitish for UV100, pale-yellowish for 2-C3/UV100, C3/UV100 and 2-C4/UV100, yellowish for iC4/UV100 and 2-C6/ UV100, and brownish for C6/UV100 and cC6/UV100. The colors shift from white to brown indicated the extent of visible light absorption influenced by carbon modification, depending on the carbon number of precursor molecule. The UV-visible absorbance spectra for various $\mathrm{TiO}_{2}$ samples can be seen in Figure 7(a). Obviously, UV100 displayed strong absorbance in UV region, corresponding to a sharp absorption edge near $380 \mathrm{~nm}$. The band gap of UV100 was well known as $3.2 \mathrm{eV}$ based on the pure anatase phase structure. In the presence of carbon residue, the visible absorbance increased with the increasing carbon number of precursor molecule for carbon-modified $\mathrm{TiO}_{2}$. Despite a little expense of UV absorbance, the modified samples still provided sufficient UV activities in De- $\mathrm{NO}_{x}$ reaction. In addition, the optical absorption edges of carbon-modified $\mathrm{TiO}_{2}$ showed obvious red shifts and long absorption tailing over $700 \mathrm{~nm}$ in visible region, especially in samples of C6/UV100 and cC6/UV100. This phenomenon implied certain change in band gap structure occurred due to the existence of carbon residue.

For semiconductor material, the direct band gap can be derived by establishing Tauc Plot of transformed KubelkaMunk function versus the absorbed light energy [37]. As can be seen in Figure 7(b), the so-called Tauc optical band gap is obtained at the intercept between the extension line of slop and the base line. For example, the band gap of UV100 is calculated as $3.26 \mathrm{eV}$ from the Tauc Plot, corresponding to the wavelength of $380 \mathrm{~nm}$. The direct band gaps were thus calculated and listed in Table 1 (Column 2). The band gap reduced with increasing carbon number of precursor molecule, which evidenced that the alcoholic modification certainly made a red shift and thus the absorption of visible light. The red shift essentially provided the activity of catalyst under the visible light illumination.

For carbon-modified $\mathrm{TiO}_{2}$, there exist two types of structure, that is, oxygen substitution to form Ti-C bonding and carbon residue deposition in the form of carbonate species $(\mathrm{C}=\mathrm{O})$. In former case, a subband gap may be created to show both main peak and shoulder peak in UV-Vis spectrum [27, 38]. In the latter case, the carbon residues are usually deposited on the interfaces or surface of $\mathrm{TiO}_{2}$, making a red shift in UV-VIS spectrum [39]. In this study, obvious red shift was found for carbon-modified $\mathrm{TiO}_{2}$ samples. Therefore, the formation of carbonate species was expected.

\subsubsection{XPS Analysis}

Analysis of Chemical Elements. XPS analysis revealed the elemental surface composition of the samples, including $\mathrm{Ti}$, $\mathrm{O}, \mathrm{N}$, and $\mathrm{C}$, as summarized in Table 2. According to the synthesis procedure, element $\mathrm{N}$ was not detectable in the carbon-modified $\mathrm{TiO}_{2}$ sample as expected, while trace $\mathrm{N}$ was detected in UV100 catalyst probably introduced with stray ions in the commercial manufacturing process. The composition of elements $\mathrm{Ti}$ and $\mathrm{O}$ and its atomic ratio of $\mathrm{O} / \mathrm{Ti}$ are demonstrated in Table 2. The atomic ratios of $\mathrm{O} / \mathrm{Ti}$ were in range of $2.6-4.3$, greater than theoretical value of 2, probably due to the surface phydrophilicity. Carbonmodified $\mathrm{TiO}_{2}$ showed lower O/Ti ratio than that of UV100 (3.8), indicating the decrease of hydrophilicity caused by the existence of carbon residue. The carbon content showed relatively high values in range of $24.0-43.7 \%$. The carbon might come from two sources: adventitious element carbon from the impurity of equipment chamber [36], and carbon residues from the impregnation of alcoholic precursor. The carbon content detected in UV100 could be regarded as the baseline amount of adventitious element carbon. The content higher than that baseline could be determined as 


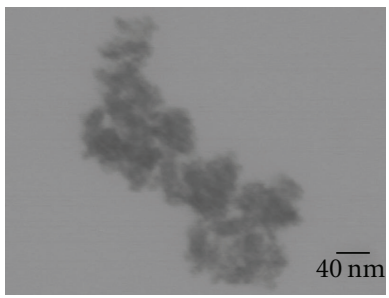

(a)

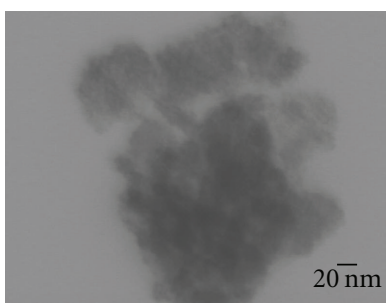

(c)

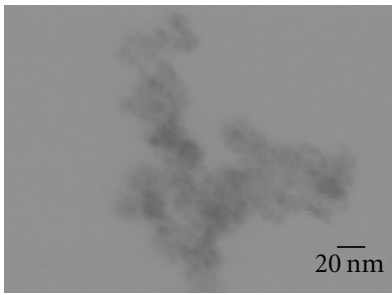

(b)

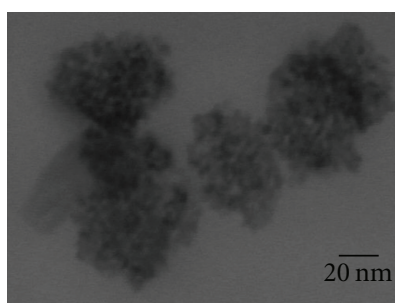

(d)

(A)

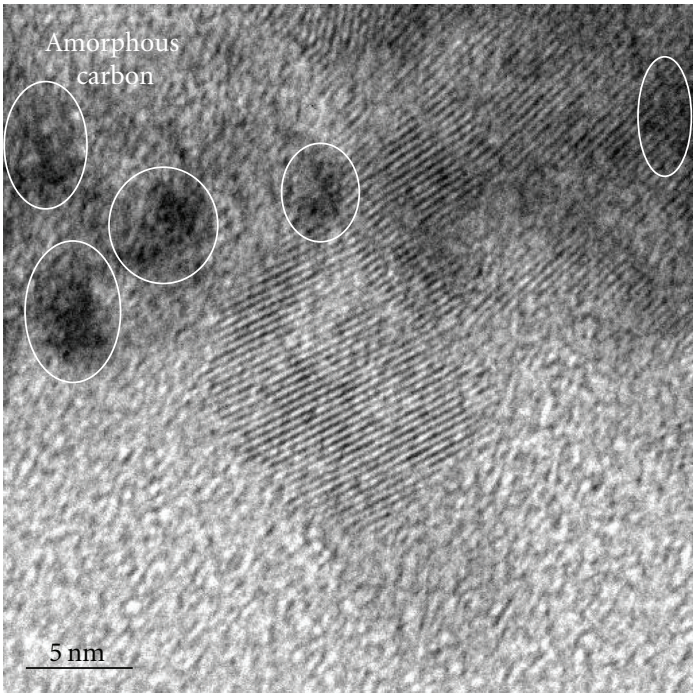

(B)

Figure 4: FE-SEM images (A) of UV100 (a), C3/UV100 (b), C6/UV100 (c), and cC6/UV100 (d) and TEM image of cC6/UV100 (B).

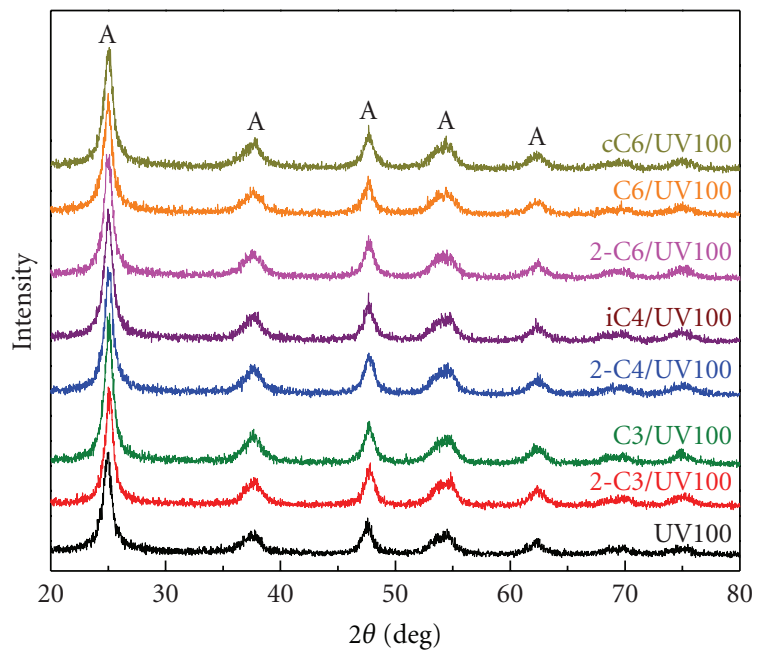

FIGURE 5: XRD patterns of the photocatalysts.

the amount of carbon residues from impregnated alcoholic precursor. Obviously, the higher the carbon number of precursor molecule was, the larger amount of carbon residue was obtained.

Analysis of Chemical States. Ti 2p, C 1s, and O 1s spectra were conducted for analysis of chemical states. No difference was found in $\mathrm{Ti} 2 \mathrm{p}$ spectrum (not shown here) for various samples, indicating no change of surface Ti bonding occurred because of the impregnation of carbon precursor. For C 1s spectrum (Figure 8(a)), two peaks at $284.5 \mathrm{eV}$ and 287-288 eV were observed for all the carbon-modified samples, except for the original UV100 sample. The peak at $284.5 \mathrm{eV}$ denoted $\mathrm{C}-\mathrm{C}$ bonding caused by adventitious element carbon. The peak at $287-288 \mathrm{eV}$ denoted $\mathrm{C}=\mathrm{O}$ bonding represented by carbonate species. All the carbonmodified samples showed higher intensity of $\mathrm{C}=\mathrm{O}$ peak than that of UV100, indicating the effect of carbon residues. Also, the intensity increased with increasing carbon number of precursor molecule. For O 1s spectrum (Figure 8(b)), three kinds of peaks, that is, Ti-O $(529-530 \mathrm{eV}), \mathrm{O}-\mathrm{H}(531 \mathrm{eV})$, and $\mathrm{C}=\mathrm{O}(532 \mathrm{eV})$, could be observed. Ti-O bonding is the main peak of $\mathrm{TiO}_{2}$ and can be seen in all the samples. $\mathrm{O}-\mathrm{H}$ bonding might be introduced by the hydrophilicity of water vapor to form the surface-bound hydroxyl group [1]. The third one was $\mathrm{C}=\mathrm{O}$ bonding which represented the occurrence of carbonate species due to the carbon modification. Therefore, the intensity of $\mathrm{C}=\mathrm{O}$ bonding increased with increasing carbon number of precursor molecule, which was consistent with the results from $\mathrm{C}$ 1s spectrum.

To further investigate the contribution of individual bonding, the ratio of two peaks in $\mathrm{C} 1 \mathrm{~s}$ and three peaks in $\mathrm{O}$ 1s spectrum would be calculated separately. Deconvolution method was thus conducted to calculate the ratio of each bonding. Taking examples of UV100 and cC6/UV100, the peaks of $\mathrm{C}=\mathrm{O}$ and $\mathrm{C}-\mathrm{C}$ bonding in $\mathrm{C} 1$ s spectrum could be separated and the ratio could be calculated by the integration area, as shown in Figure 9(a). The same procedure could be conducted for O 1s spectrum (Figure 9(b)). Using deconvolution method, the ratio of each bonding in all samples could be calculated and listed in Table 3 .

For C 1s analysis, adventitious element carbon (represented by $\mathrm{C}-\mathrm{C}$ bonding) possessed the ratio of $18.8-$ $31.4 \%$ and no obvious trend among the samples was observed due to the characteristics of adventive impurity itself. In contrast, carbonate species (represented by $\mathrm{C}=\mathrm{O}$ bonding) showed obvious trend with the carbon number of precursor molecule. In UV100 sample, only trace carbonate species $(1.4 \%)$ were observed. In carbon-modified samples, 


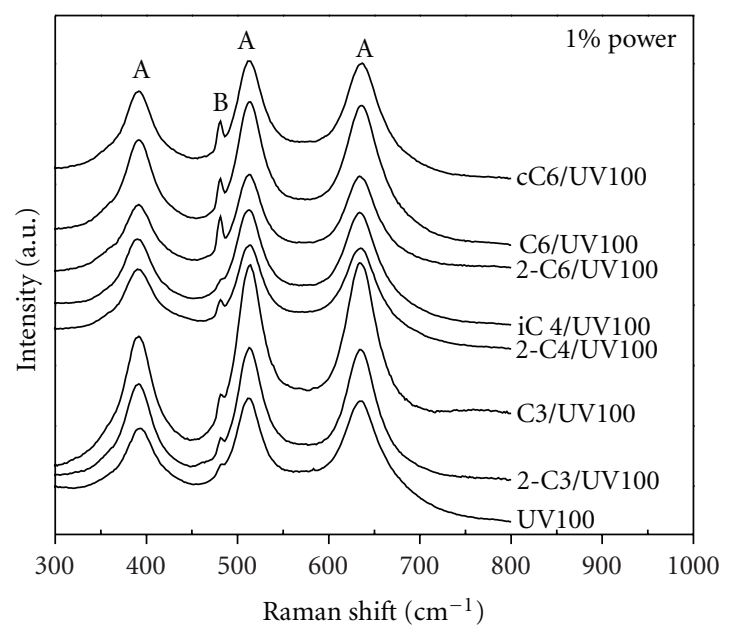

(a)

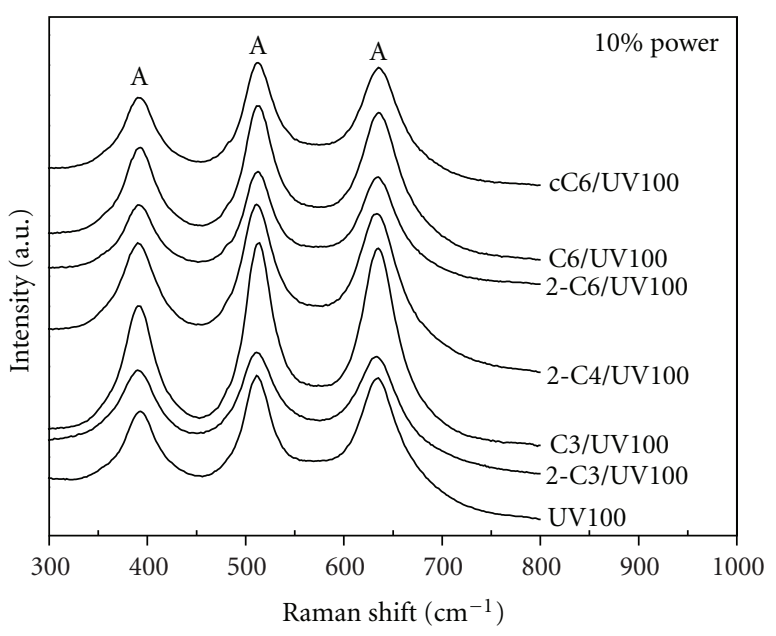

(b)

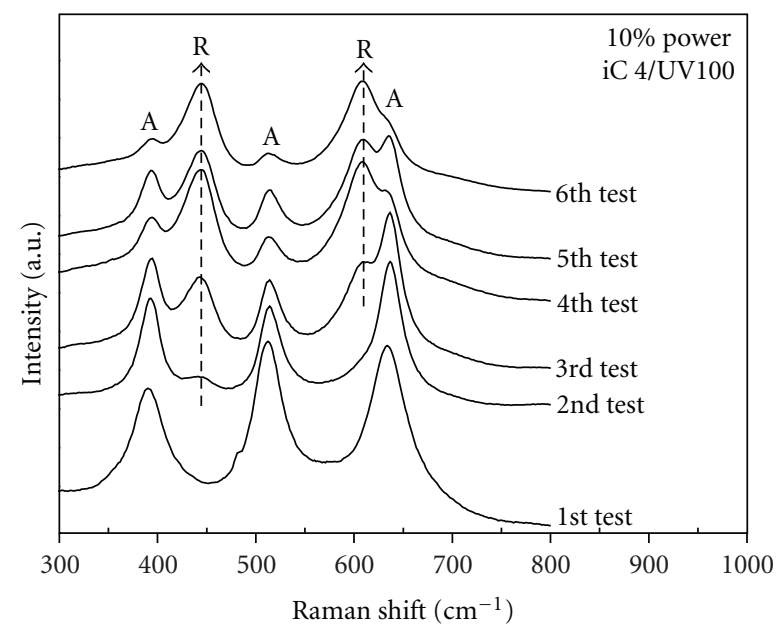

(c)

FIgURE 6: Raman spectra with 1\% (a) and 10\% (b) power for all samples; 10\% power for iC4/UV100 over 6 times of test (c).

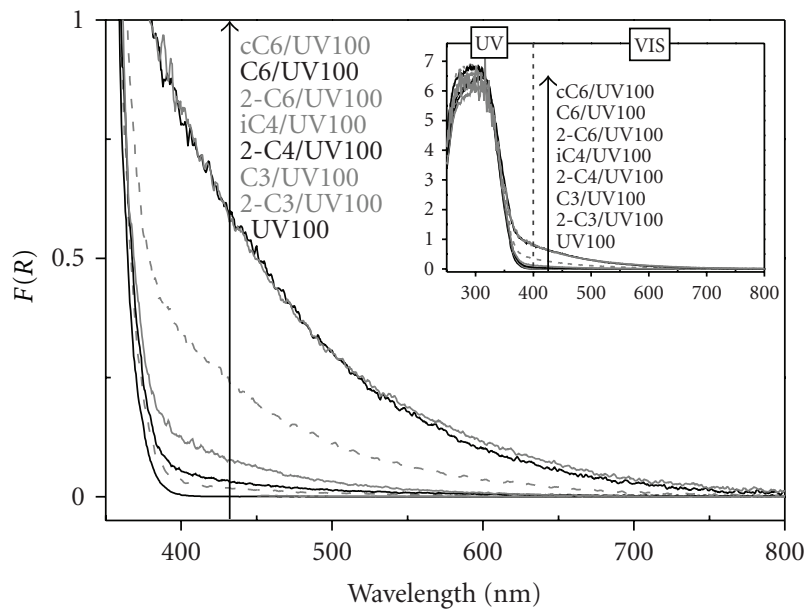

(a)

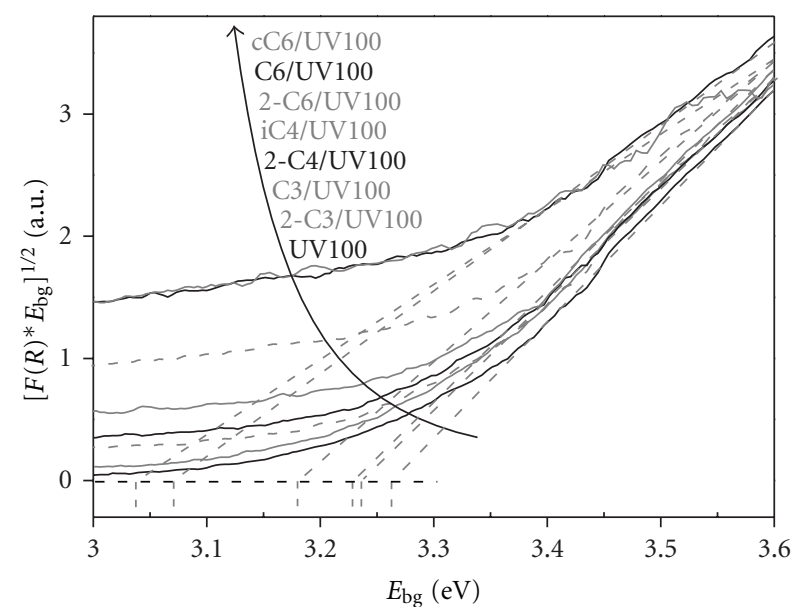

(b)

FIgURE 7: UV-visible absorption spectra (a) and the plot of transformed Kubelka-Munk function versus the energy band gap (b). 


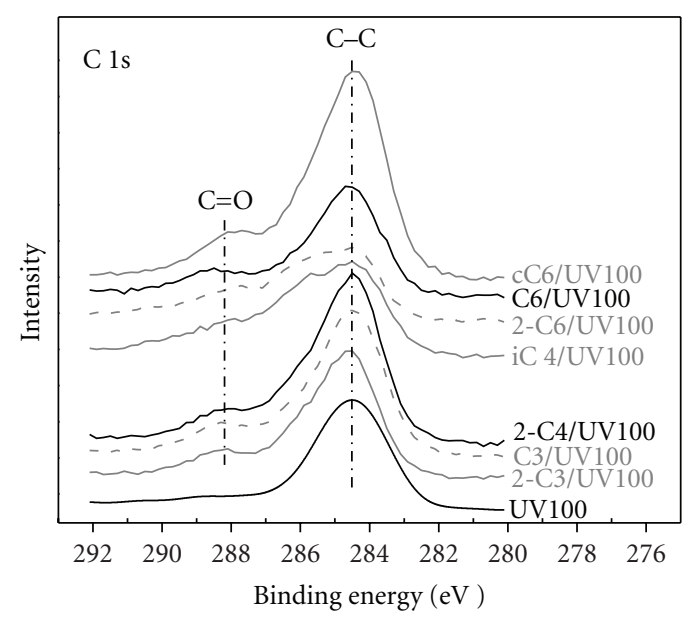

(a)

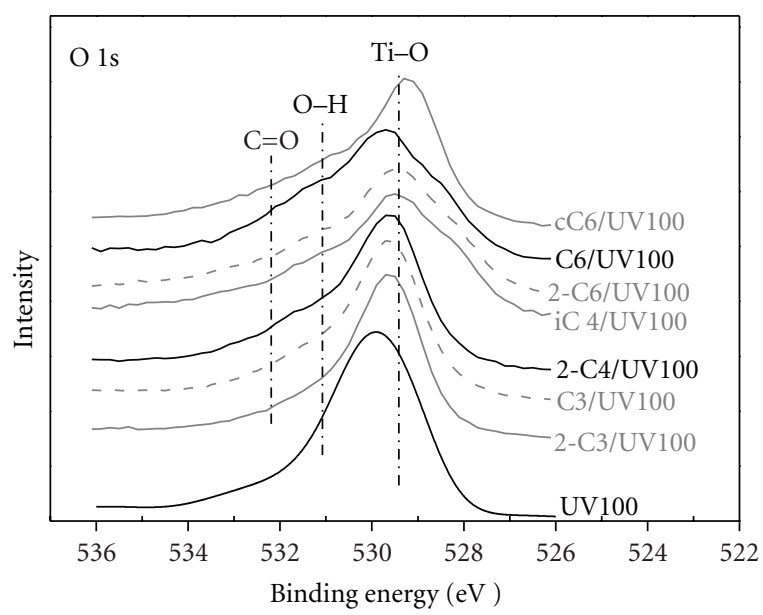

(b)

Figure 8: C 1s (a) and O 1s (b) XPS spectra for all samples.
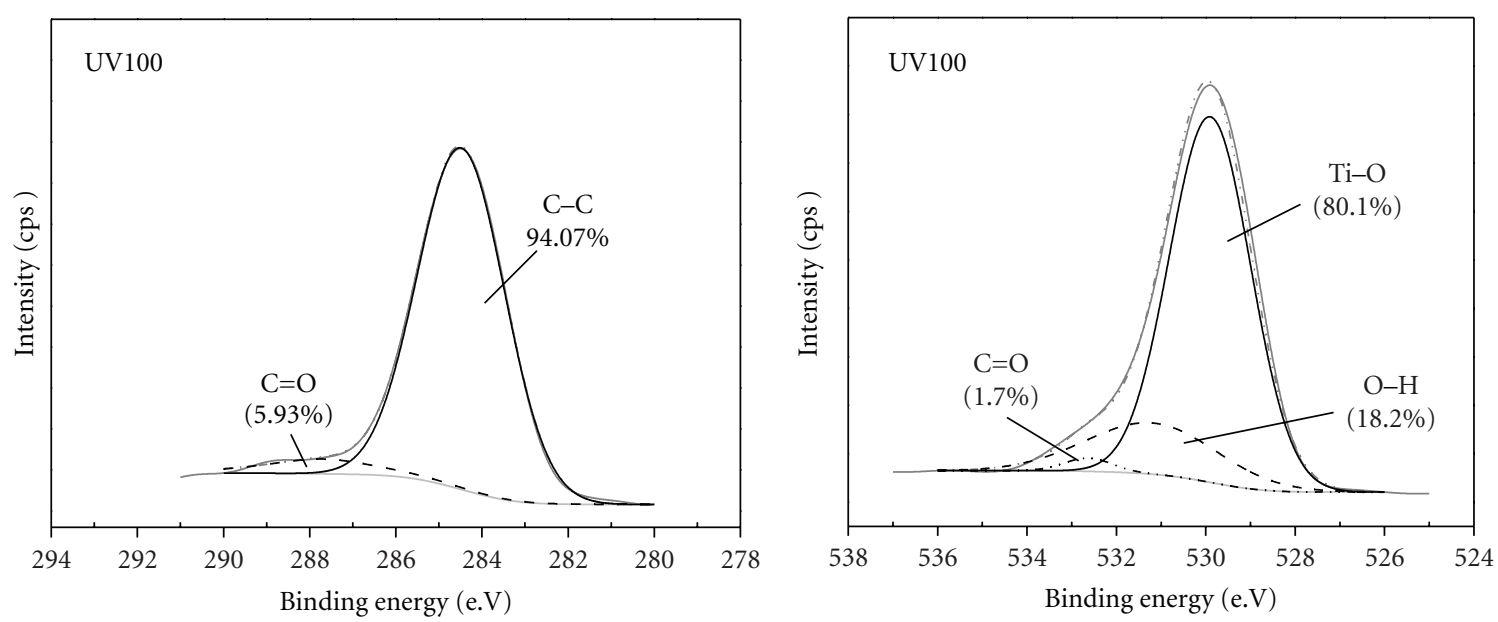

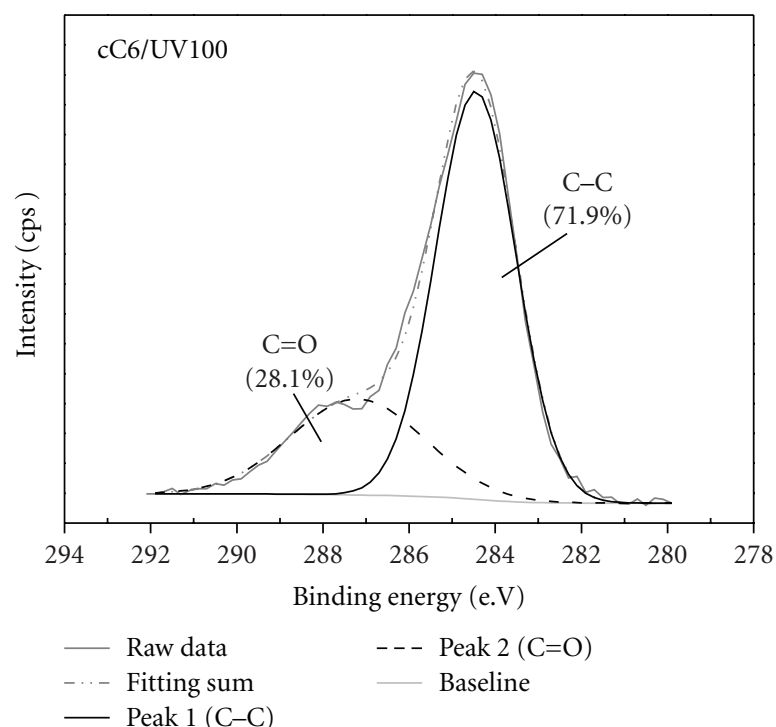

(a)

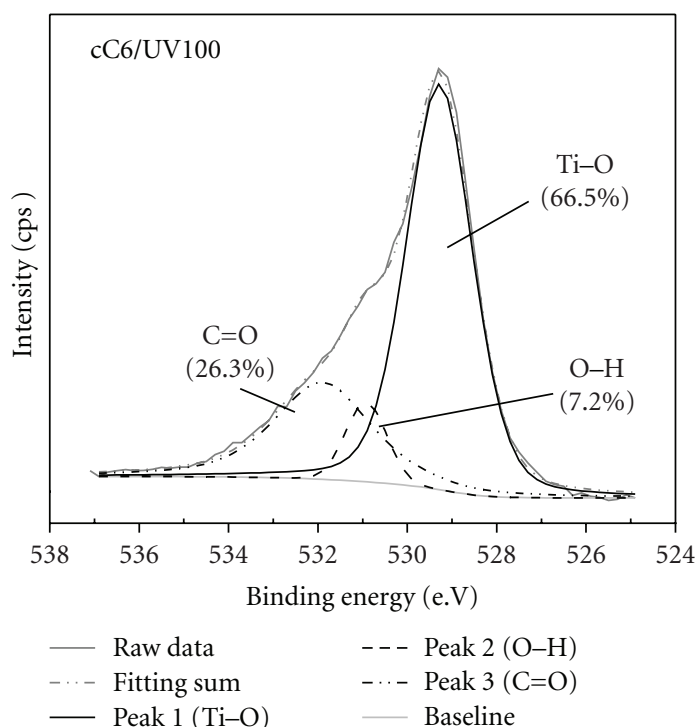

(b)

FIgURe 9: Deconvolution of C 1s (a) and O 1s (b) XPS spectra for UV100 and cC6/UV100. 


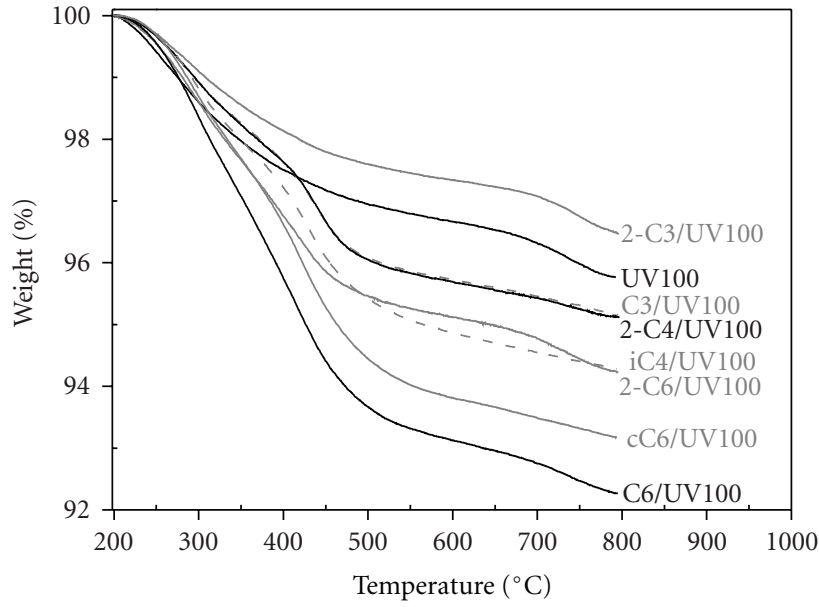

(a)

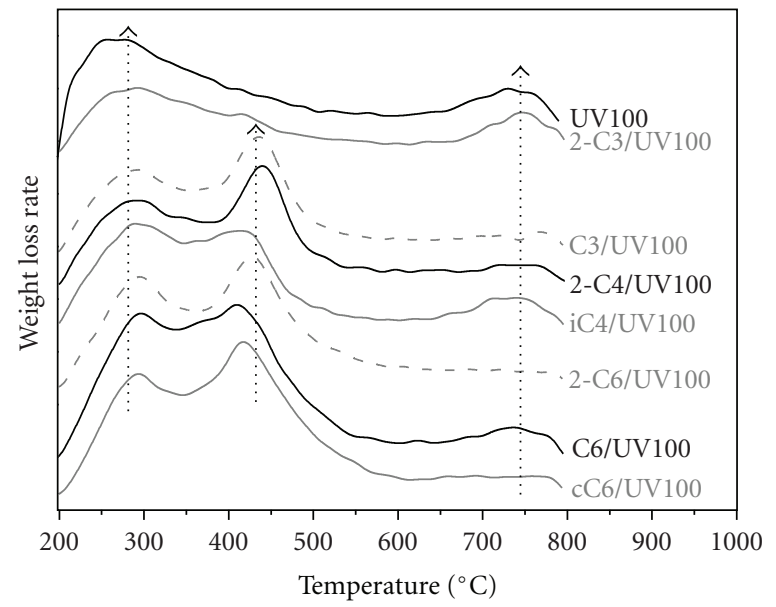

(b)

Figure 10: TGA (a) and DTG (b) curves for all samples obtained in flowing $\mathrm{N}_{2}$.

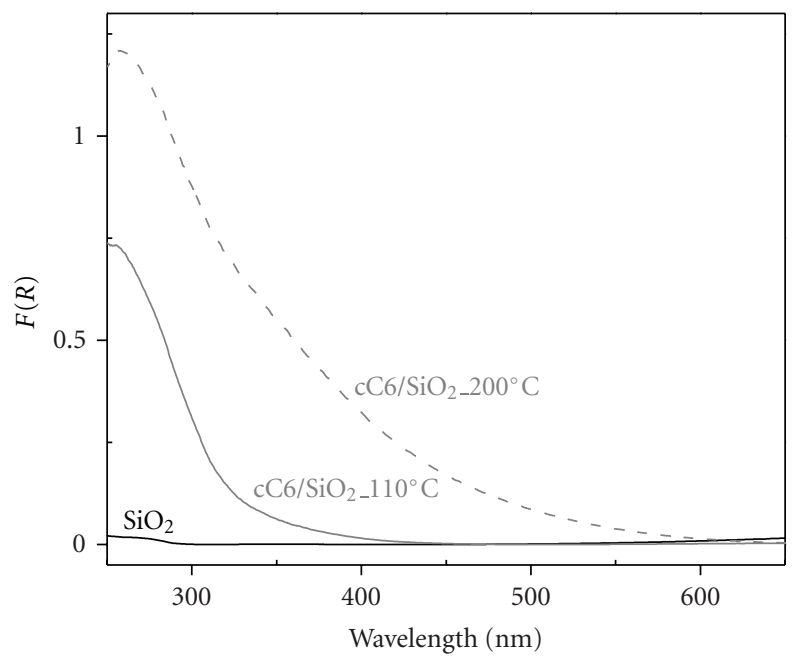

Figure 11: UV-visible absorption spectra for $\mathrm{SiO}_{2}$, cC6/ $\mathrm{SiO}_{2} \_110^{\circ} \mathrm{C}$, and $\mathrm{cC} 6 / \mathrm{SiO}_{2} \_200^{\circ} \mathrm{C}$.

the amount of carbonate species clearly increased with increasing carbon number of precursor molecule.

For $\mathrm{O} 1 \mathrm{~s}$ analysis, Ti-O bonding possessed major portion as expected in $\mathrm{TiO}_{2}$ matrix. The ratio of $\mathrm{O}-\mathrm{H}$ bonding showed great difference between UV100 and carbonmodified $\mathrm{TiO}_{2}$ samples. High ratio of $\mathrm{O}-\mathrm{H}$ bonding (10.7\%) exhibited high hydrophilicity of UV100. However, low ratio of $\mathrm{O}-\mathrm{H}$ bonding $(2.6-3.7 \%)$ implied low hydrophilicity of carbon-modified $\mathrm{TiO}_{2}$, as described in literature [40, 41]. Carbonate species (represented by $\mathrm{C}=\mathrm{O}$ bonding) showed obvious trend with the carbon number of precursor molecule, consistent with the result from $\mathrm{C}$ 1s analysis. In UV100 sample, only trace carbonate species (1.0\%) were observed. In carbon-modified samples, the amount of carbonate species clearly increased with increasing carbon number of precursor molecule. In summary, the trend of carbonate species is in good correlation with the visible light absorption and photoactivity of nitrogen oxides degra-

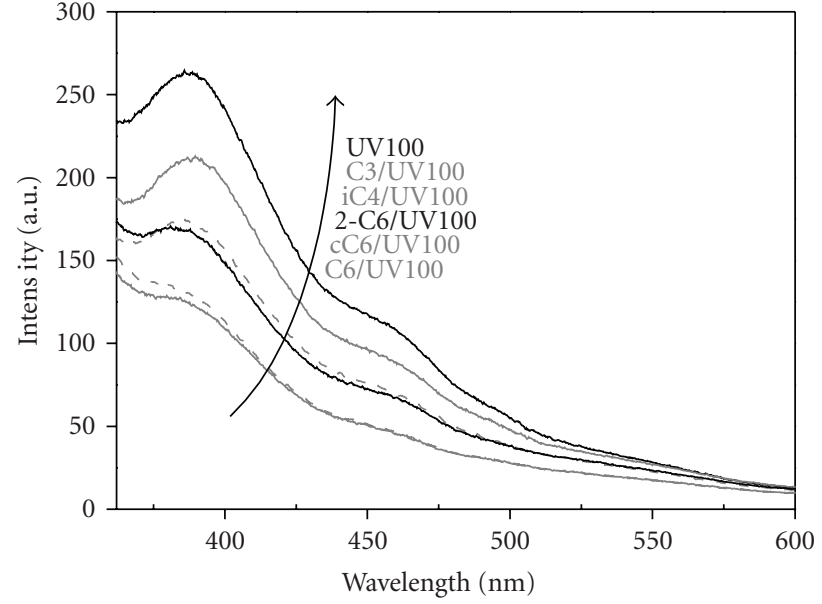

Figure 12: PL spectra for UV100, C3/UV100, iC4/UV100, 2C6/UV100, C6/UV100, and cC6/UV100. Excitation light source: Xe lamp with wavelength of $325 \mathrm{~nm}$.

dation under visible light illumination. Therefore, it can be concluded that the carbonate species may make major contributions for visible-light-active photocatalysis.

3.2.6. Thermogravimetric Analysis (TGA). Figure 10(a) shows TGA spectra of samples over the temperature range of $200-800^{\circ} \mathrm{C}$ under nitrogen atmosphere. All the samples were preheated at $200^{\circ} \mathrm{C}$ to remove the physical adsorbed water $[42,43]$. Figure 10(b) shows DTG spectra of samples, resulted from first derivation of TGA curves, to indicate the rate of weight loss. Three weight loss zones could be categorized as follows: Zone I: $200-380^{\circ} \mathrm{C}$, weight loss from chemical adsorbed water and some low-temperature volatile carbon residues; Zone II: $380-600^{\circ} \mathrm{C}$, weight loss from the high-temperature pyrolytic carbon species, that is, carbonate species mainly; and Zone III: $600-800^{\circ} \mathrm{C}$, weight loss probably accompanied with collapse of interagglomerate 


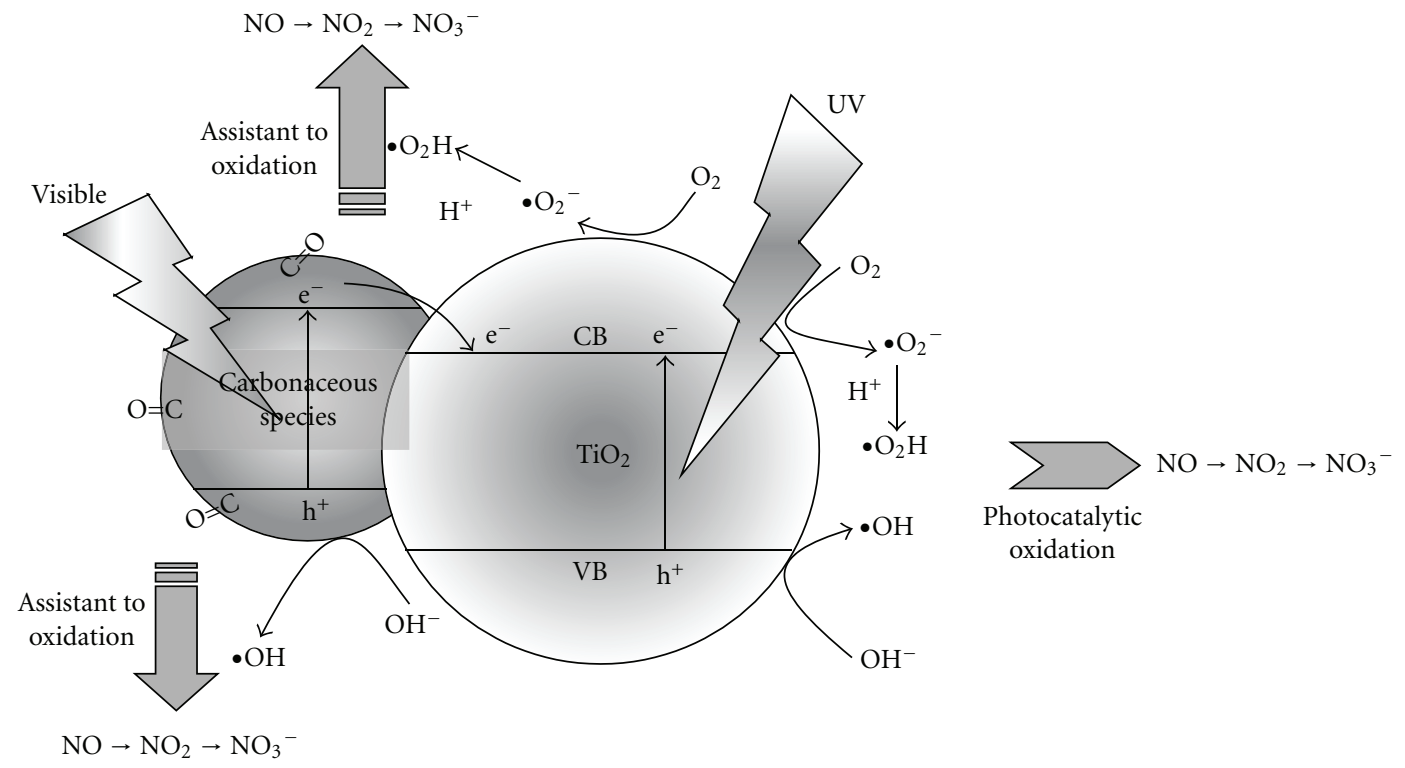

FIGURE 13: Schematic illustration of photocatalytic mechanism on carbon-modified $\mathrm{TiO}_{2}$.

and escape of trace moiety during the phase transformation from anatase to rutile [43-45]. The weight loss data was summarized in Table 1 (Column 4-7). The total weight loss of each sample was in range of $3.53-7.73 \%$. The distributions in Zone I and Zone III could be found in each sample, ascribed to the common properties of all the samples. However, the weight loss in Zone II showed different trend and obviously increased with increasing carbon number of precursor molecule. As a result, large amount of carbon residues were existed on $\mathrm{TiO}_{2}$ sample modified by precursor with large carbon number. And carbonate species should be the main composition according to the XPS analysis as discussed earlier.

\subsection{Role of Carbonate Species in Mechanism of Photocatalytic Reaction}

3.3.1. Visible Light Absorption of Carbonate Species. In this paper, we already proved that carbonate species could be formed onto interfaces or surface of $\mathrm{TiO}_{2}$ by impregnating alcoholic precursor and calcining at $200^{\circ} \mathrm{C}$. The prepared carbon-modified $\mathrm{TiO}_{2}$ illustrated obvious visible light absorption. To verify the absorption property mainly originated from the carbonate species, we prepared the sample with carbon residue on fumed silica by using cyclohexanol as precursor. Two calcination temperatures $\left(110^{\circ} \mathrm{C}\right.$ and $\left.200^{\circ} \mathrm{C}\right)$ were employed. The sample calcined at $110^{\circ} \mathrm{C}$ was denoted as cC6 $/ \mathrm{SiO}_{2}-110^{\circ} \mathrm{C}$ and the other at $200^{\circ} \mathrm{C}$ as cC6/SiO ${ }_{2} 200^{\circ} \mathrm{C}$. The UV-Vis spectra of carbon deposited $\mathrm{SiO}_{2}$ are shown in Figure 11. $\mathrm{SiO}_{2}$ sample exhibited no absorbance of light. The light absorbance of carbon deposited $\mathrm{SiO}_{2}$ increased with rising calcination temperature, where absorbance was higher at $200^{\circ} \mathrm{C}$ than that at $110^{\circ} \mathrm{C}$. The enhancement of absorbance may be attributed to the existence of conjugate structure in the carbon species $[30,34,46]$. Long alkyl chain or cyclic configuration of alcoholic precursor might favor the formation of conjugate structure in carbonate species. Therefore, the precursor with high carbon number of molecule could make better visible light absorption and then the photocatalytic activity.

3.3.2. Photoluminescence(PL) Emission Spectra. Photoluminescence emission occurs when a short wavelength (e.g., $32 \mathrm{~nm}$ ) photoenergy is absorbed to excite an electron from valence band and then a longer wavelength luminescence is emitted via recombination of electron-hole pair. The higher the intensity of luminescence is, the faster is the recombination of electron and hole. Therefore, high intensity of luminescence may imply low photocatalytic activity [47]. As shown in Figure 12, UV100 had the highest intensity of luminescence which meant the lowest photocatalytic activity as discussed in previous paragraph. The intensity of modified sample decreased with increasing carbon number of precursor molecule. The sample modified with cyclohexanol, cC6/UV100, showed the much lower intensity of luminescence and led to higher photocatalytic activity, especially in visible region (Figure 3 ). This suppression of luminescence might be due to the existence of carbonate species, which acted as the sensitizing agent of $\mathrm{TiO}_{2}$ and prohibitor of electron-hole recombination.

\subsubsection{Photocatalytic Mechanism on Carbon-Modified $\mathrm{TiO}_{2}$.} In summary, a mechanism of photocatalytic degradation of nitrogen oxides over carbon-modified $\mathrm{TiO}_{2}$ might be proposed in Figure 13. According to the mechanism, the carbonate species in carbon residue on $\mathrm{TiO}_{2}$ surface were regarded as the sensitizer to absorb visible light and induce the electron-hole pair of $\mathrm{TiO}_{2}$ so that hydroxyl radicals $(\bullet \mathrm{OH})$ or superoxide ions $\left(\bullet \mathrm{O}_{2}{ }^{-}\right)$, which may transform to $-\mathrm{O}_{2} \mathrm{H}$ with $\mathrm{H}^{+}$in humid environment, could be generated 
as active species for oxidation reaction [29]. The existence of carbonate species could also suppressed the recombination rate of electron-hole pair to enhance the photocatalytic activity. In addition, the carbonate species acted as promoter for deep oxidation in the degradation of nitrogen oxides and lower the selectivity of $\mathrm{NO}_{2}$. Therefore, highly active visible light photocatalyst could be achieved by carbonmodified $\mathrm{TiO}_{2}$.

\section{Conclusions}

An active visible light photocatalyst was prepared by impregnation method using a range of alcohols, that is, from propanol to cyclohexanol, as precursor to modify $\mathrm{TiO}_{2}$ powder. The prepared carbon-modified $\mathrm{TiO}_{2}$ showed better photoactivity of nitrogen oxides degradation than that of unmodified $\mathrm{TiO}_{2}$. The activity increased with increasing carbon number of alcoholic precursor. The form of carbonate species on carbon-modified $\mathrm{TiO}_{2}$ was identified by XPS and TGA analysis. A photocatalytic mechanism was thus proposed for photodegradation of nitrogen oxides. According to the mechanism, the carbonate species in carbon residue onto $\mathrm{TiO}_{2}$ interfaces or surface acted as sensitizer for visible light response, prohibitor for electronhole recombination, and promoter for oxidation of nitrogen oxides. High carbon number of alcoholic precursor would make high amount of carbonate species so that better performance of photocatalysis could be achieved.

\section{Acknowledgment}

The authors gratefully express thanks for the assistance of Micro-Raman spectrometer provided by Professor ChiaLiang Cheng (Department of Physics, National Dong Hwa University).

\section{References}

[1] M. R. Hoffmann, S. T. Martin, W. Choi, and D. W. Bahnemann, "Environmental applications of semiconductor photocatalysis," Chemical Reviews, vol. 95, no. 1, pp. 69-96, 1995.

[2] M. A. Fox and M. T. Dulay, "Heterogeneous photocatalysis," Chemical Reviews, vol. 93, no. 1, pp. 341-357, 1993.

[3] A. Mills, R. H. Davies, and D. Worsley, "Water purification by semiconductor photocatalysis," Chemical Society Reviews, vol. 22, no. 6, pp. 417-425, 1993.

[4] S. Devahasdin, C. Fan Jr., K. Li, and D. H. Chen, "TiO 2 photocatalytic oxidation of nitric oxide: transient behavior and reaction kinetics," Journal of Photochemistry and Photobiology A, vol. 156, no. 1-3, pp. 161-170, 2003.

[5] D. F. Ollis, E. Pelizzetti, and N. Serpone, "Photocatalyzed destruction of water contaminants," Environmental Science and Technology, vol. 25, no. 9, pp. 1522-1529, 1991.

[6] A. Fujishima and K. Honda, "Electrochemical photolysis of water at a semiconductor electrode," Nature, vol. 238, no. 5358, pp. 37-38, 1972.

[7] A. Fujishima, T. N. Rao, and D. A. Tryk, "Titanium dioxide photocatalysis," Journal of Photochemistry and Photobiology C, vol. 1, no. 1, pp. 1-21, 2000.
[8] M. Gopal, W. J. Moberly Chan, and L. C. De Jonghe, "Room temperature synthesis of crystalline metal oxides," Journal of Materials Science, vol. 32, no. 22, pp. 6001-6008, 1997.

[9] K. E. Karakitsou and X. E. Verykios, "Effects of altervalent cation doping of $\mathrm{TiO}_{2}$ on its performance as a photocatalyst for water cleavage," Journal of Physical Chemistry, vol. 97, no. 6, pp. 1184-1189, 1993.

[10] Y. Takahashi and Y. Matsuoka, "Dip-coating of $\mathrm{TiO}_{2}$ films using a sol derived from $\mathrm{Ti}(\mathrm{O}-i \text {-Pr })_{4}$-diethanolamine- $\mathrm{H}_{2} \mathrm{O}-i$ PrOH system," Journal of Materials Science, vol. 23, no. 6, pp. 2259-2266, 1988.

[11] S. Klosek and D. Raftery, "Visible light driven V-doped $\mathrm{TiO}_{2}$ photocatalyst and its photooxidation of ethanol," Journal of Physical Chemistry B, vol. 105, no. 14, pp. 2815-2819, 2001.

[12] H. Yamashita, M. Harada, J. Misaka, M. Takeuchi, K. Ikeue, and M. Anpo, "Degradation of propanol diluted in water under visible light irradiation using metal ion-implanted titanium dioxide photocatalysts," Journal of Photochemistry and Photobiology A, vol. 148, no. 1-3, pp. 257-261, 2002.

[13] M. Anpo, M. Takeuchi, K. Ikeue, and S. Dohshi, "Design and development of titanum oxide photocatalysts operating under visible and UV light irradiation. The applications of metal ionimplantation techniqes to semiconducting $\mathrm{TiO}_{2}$ and Ti/zeolite catalysts," Current Opinion in Solid State and Materials Science, vol. 6, no. 5, pp. 381-388, 2002.

[14] Y. Sakata, T. Yamamoto, T. Okazaki, H. Imamura, and S. Tsuchiya, "Generation of visible light response on the photocatalyst of a copper ion containing $\mathrm{TiO}_{2}$," Chemistry Letters, no. 12, pp. 1253-1254, 1998.

[15] A. Fuerte, M. D. Hernández-Alonso, A. J. Maira et al., "Visible light-activated nanosized doped- $\mathrm{TiO}_{2}$ photocatalysts," Chemical Communications, vol. 24, no. 24, pp. 2718-2719, 2001.

[16] A. L. Linsebigler, G. Lu, and J. T. Yates Jr., "Photocatalysis on $\mathrm{TiO}_{2}$ surfaces: principles, mechanisms, and selected results," Chemical Reviews, vol. 95, no. 3, pp. 735-758, 1995.

[17] J. M. Herrmann, H. Tahiri, Y. Ait-Ichou, G. Lassaletta, A. R. González-Elipe, and A. Fernandez, "Characterization and photocatalytic activity in aqueous medium of $\mathrm{TiO}_{2}$ and Ag$\mathrm{TiO}_{2}$ coatings on quartz," Applied Catalysis B, vol. 13, no. 3-4, pp. 219-228, 1997.

[18] T. Ohno, F. Tanigawa, K. Fujihara, S. Izumi, and M. Matsumura, "Photocatalytic oxidation of water by visible light using ruthenium-doped titanium dioxide powder," Journal of Photochemistry and Photobiology A, vol. 127, no. 1-3, pp. 107110, 1999.

[19] H. Kisch, L. Zang, C. Lange, W. F. Maier, C. Antonius, and D. Meissner, "Modified, amorphous titania-a hybrid semiconductor for detoxification and current generation by visible light," Angewandte Chemie, vol. 37, no. 21, pp. 30343036, 1998.

[20] C. H. Huang, I. K. Wang, Y. M. Lin, Y. H. Tseng, and C. M. Lu, "Visible light photocatalytic degradation of nitric oxides on PtOx-modified $\mathrm{TiO}_{2}$ via sol-gel and impregnation method," Journal of Molecular Catalysis A, vol. 316, no. 1-2, pp. 163-170, 2010.

[21] Y. M. Lin, Y. H. Tseng, J. H. Huang, C. C. Chao, C. C. Chen, and I. Wang, "Photocatalytic activity for degradation of nitrogen oxides over visible light responsive titania-based photocatalysts," Environmental Science and Technology, vol. 40, no. 5, pp. 1616-1621, 2006.

[22] S. Sato, "Photocatalytic activity of $\mathrm{NO}_{\mathrm{X}}$-doped $\mathrm{TiO}_{2}$ in the visible light region," Chemical Physics Letters, vol. 123, no. 1-2, pp. 126-128, 1986. 
[23] R. Asahi, T. Morikawa, T. Ohwaki, K. Aoki, and Y. Taga, "Visible-light photocatalysis in nitrogen-doped titanium oxides," Science, vol. 293, no. 5528, pp. 269-271, 2001.

[24] I. Nakamura, N. Negishi, S. Kutsuna, T. Ihara, S. Sugihara, and K. Takeuchi, "Role of oxygen vacancy in the plasma-treated $\mathrm{TiO}_{2}$ photocatalyst with visible light activity for NO removal," Journal of Molecular Catalysis A, vol. 161, no. 1-2, pp. 205-212, 2000.

[25] C. Nasr, K. Vinodgopal, L. Fisher, S. Hotchandani, A. K. Chattopadhyay, and P. V. Kamat, "Environmental photochemistry on semiconductor surfaces. Visible light induced degradation of a textile diazo dye, naphthol blue black, on $\mathrm{TiO}_{2}$ nanoparticles," Journal of Physical Chemistry, vol. 100, no. 20, pp. 8436-8442, 1996.

[26] T. Wu, G. Liu, J. Zhao, H. Hidaka, and N. Serpone, "Evidence for $\mathrm{H}_{2} \mathrm{O}_{2}$ generation during the $\mathrm{TiO}_{2}$-assisted photodegradation of dyes in aqueous dispersions under visible light illumination," Journal of Physical Chemistry B, vol. 103, no. 23, pp. 4862-4867, 1999.

[27] S. U. M. Khan, M. Al-Shahry, and W. B. Ingler, "Efficient photochemical water splitting by a chemically modified n$\mathrm{TiO}_{2}$," Science, vol. 297, no. 5590, pp. 2243-2245, 2002.

[28] S. Sakthivel and H. Kisch, "Daylight photocatalysis by carbonmodified titanium dioxide," Angewandte Chemie, vol. 42, no. 40, pp. 4908-4911, 2003.

[29] Y. H. Tseng, C. S. Kuo, C. H. Huang et al., "Visible-lightresponsive nano- $\mathrm{TiO}_{2}$ with mixed crystal lattice and its photocatalytic activity," Nanotechnology, vol. 17, no. 10, pp. 2490-2497, 2006.

[30] Y. Ou, J. Lin, S. Fang, and D. Liao, "MWNT-TiO ${ }_{2}: \mathrm{Ni}$ composite catalyst: a new class of catalyst for photocatalytic $\mathrm{H}_{2}$ evolution from water under visible light illumination," Chemical Physics Letters, vol. 429, no. 1-3, pp. 199-203, 2006.

[31] S. Y. Treschev, P. W. Chou, Y. H. Tseng, J. B. Wang, E. V. Perevedentseva, and C. L. Cheng, "Photoactivities of the visible-light-activated mixed-phase carbon-containing titanium dioxide: the effect of carbon incorporation," Applied Catalysis B, vol. 79, no. 1, pp. 8-16, 2008.

[32] I. C. Kang, Q. Zhang, S. Yin, T. Sato, and F. Saito, "Preparation of a visible sensitive carbon doped $\mathrm{TiO}_{2}$ photo-catalyst by grinding $\mathrm{TiO}_{2}$ with ethanol and heating treatment," Applied Catalysis B, vol. 80, no. 1-2, pp. 81-87, 2008.

[33] S. Brunauer, P. H. Emmett, and E. Teller, "Adsorption of gases in multimolecular layers," Journal of the American Chemical Society, vol. 60, no. 2, pp. 309-319, 1938.

[34] H. Jensen, K. D. Joensen, J. E. Jørgensen, J. S. Pedersen, and E. G. Søgaard, "Characterization of nanosized partly crystalline photocatalysts," Journal of Nanoparticle Research, vol. 6, no. 5, pp. 519-526, 2004.

[35] L. W. Zhang, H. B. Fu, and Y. F. Zhu, "Efficient $\mathrm{TiO}_{2}$ photocatalysts from surface hybridization of $\mathrm{TiO}_{2}$ particles with graphite-like carbon," Advanced Functional Materials, vol. 18, no. 15, pp. 2180-2189, 2008.

[36] C. S. Gopinath, S. G. Hegde, A. V. Ramaswamy, and S. Mahapatra, "Photoemission studies of polymorphic $\mathrm{CaCO}_{3}$ materials," Materials Research Bulletin, vol. 37, no. 7, pp. 13231332, 2002.

[37] J. Tauc, R. Grigorovici, and A. Vancu, "Optical properties and electronic structure of amorphous germanium," Physica Status Solidi B, vol. 15, no. 2, pp. 627-637, 1966.

[38] H. Irie, Y. Watanabe, and K. Hashimoto, "Carbon-doped anatase $\mathrm{TiO}_{2}$ powders as a visible-light sensitive photocatalyst," Chemistry Letters, vol. 32, no. 8, pp. 772-773, 2003.
[39] C. Lettmann, K. Hildenbrand, H. Kisch, W. Macyk, and W. F. Maier, "Visible light photodegradation of 4-chlorophenol with a coke-containing titanium dioxide photocatalyst," Applied Catalysis B, vol. 32, no. 4, pp. 215-227, 2001.

[40] M. Janus, M. Inagaki, B. Tryba, M. Toyoda, and A. W. Morawski, "Carbon-modified $\mathrm{TiO}_{2}$ photocatalyst by ethanol carbonisation," Applied Catalysis B, vol. 63, no. 3-4, pp. 272276, 2006

[41] A. W. Morawski, M. Janus, B. Tryba, M. Inagaki, and K. Kałucki, " $\mathrm{TiO}_{2}$-anatase modified by carbon as the photocatalyst under visible light," Comptes Rendus Chimie, vol. 9, no. 5-6, pp. 800-805, 2006.

[42] J. Yu, J. C. Yu, W. Ho et al., "Effects of alcohol content and calcination temperature on the textural properties of bimodally mesoporous titania," Applied Catalysis A, vol. 255, no. 2, pp. 309-320, 2003.

[43] K. C. Song and S. E. Pratsinis, "The effect of alcohol solvents on the porosity and phase composition of Titania," Journal of Colloid and Interface Science, vol. 231, no. 2, pp. 289-298, 2000.

[44] J. Yu, X. Zhao, and Q. Zhao, "Effect of surface structure on photocatalytic activity of $\mathrm{TiO}_{2}$ thin films prepared by sol-gel method," Thin Solid Films, vol. 379, no. 1-2, pp. 7-14, 2000.

[45] J. F. Porter, Y. G. Li, and C. K. Chan, "Effect of calcination on the microstructural characteristics and photoreactivity of Degussa P-25 $\mathrm{TiO}_{2}$," Journal of Materials Science, vol. 34, no. 7, pp. 1523-1531, 1999.

[46] K. Dai, T. Peng, D. Ke, and B. Wei, "Photocatalytic hydrogen generation using a nanocomposite of multi-walled carbon nanotubes and $\mathrm{TiO}_{2}$ nanoparticles under visible light irradiation," Nanotechnology, vol. 20, no. 12, Article ID 125603, 2009.

[47] Y. Yu, J. C. Yu, J. G. Yu et al., "Enhancement of photocatalytic activity of mesoporous $\mathrm{TiO}_{2}$ by using carbon nanotubes," Applied Catalysis A, vol. 289, no. 2, pp. 186-196, 2005. 


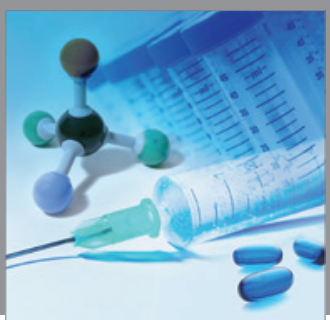

International Journal of

Medicinal Chemistry

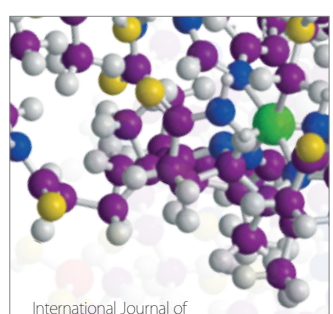

Carbohydrate Chemistry

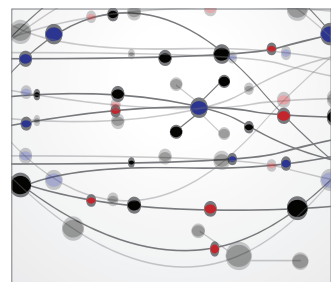

The Scientific World Journal
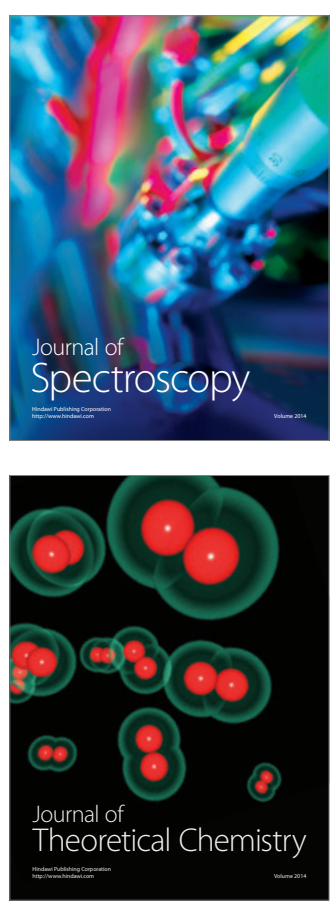
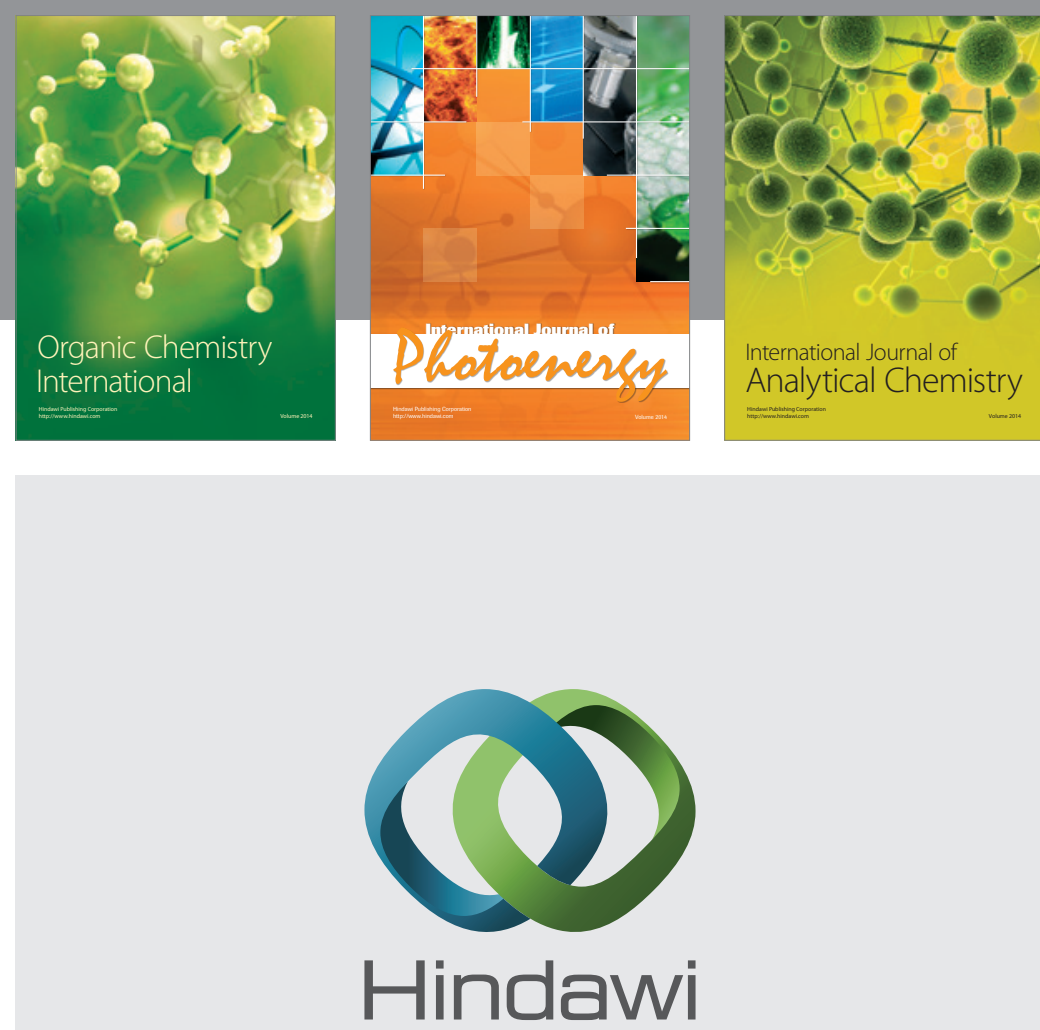

Submit your manuscripts at

http://www.hindawi.com
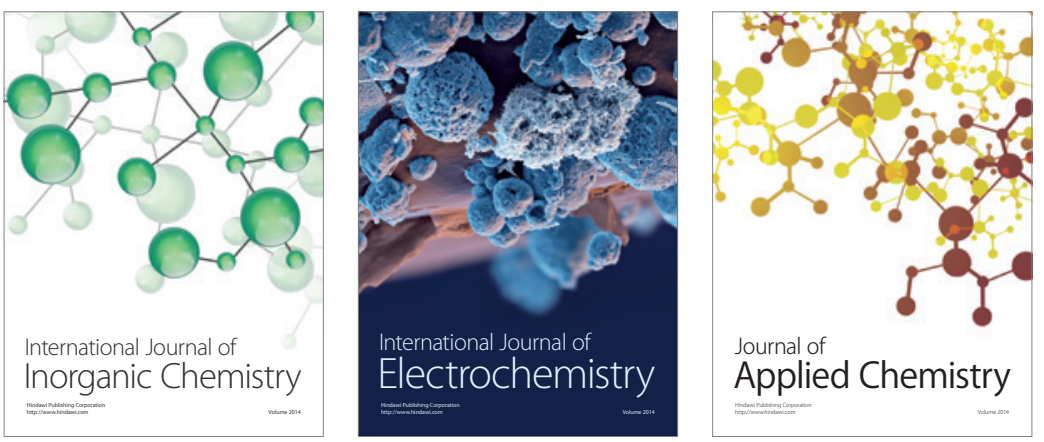

Journal of

Applied Chemistry
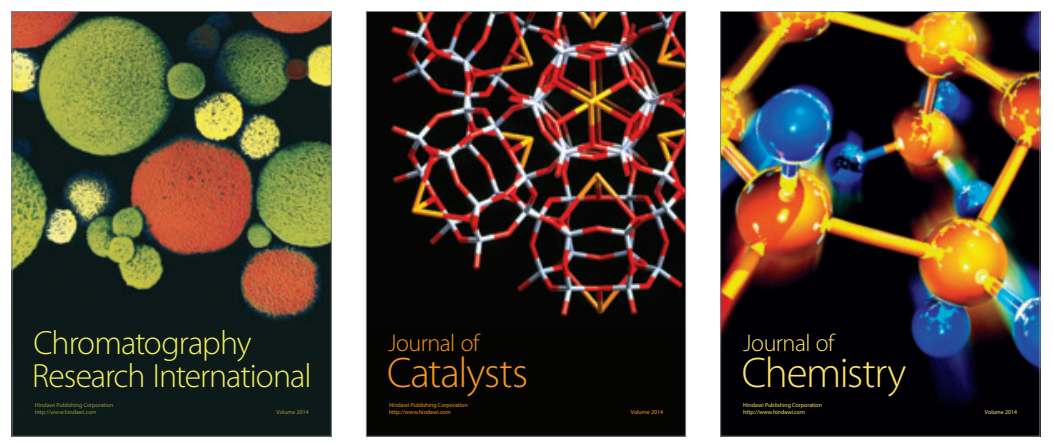
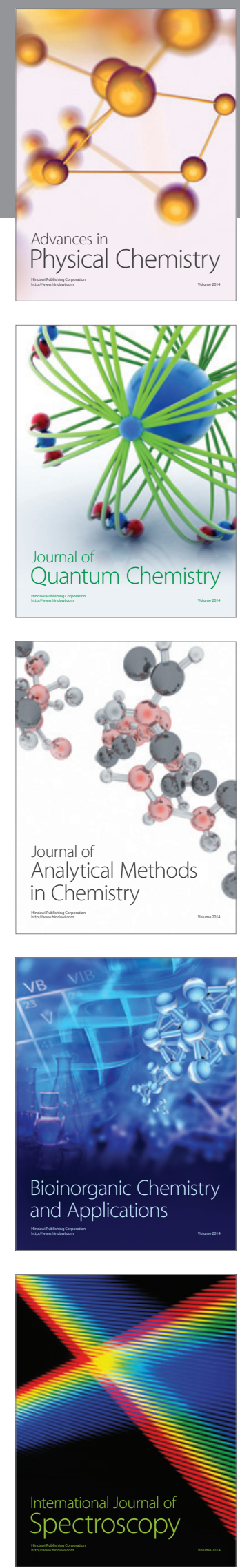